\title{
Time-lapse imaging of cleavage divisions in embryo quality assessment
}

\author{
Robert Milewski ${ }^{1, *}$ and Anna Ajduk ${ }^{2, *}$ \\ ${ }^{1}$ Department of Statistics and Medical Informatics, Medical University of Bialystok, Bialystok, Poland, and \\ ${ }^{2}$ Department of Embryology, Faculty of Biology, University of Warsaw, Warsaw, Poland \\ Correspondence should be addressed to R Milewski or A Ajduk; Email: robert.milewski@umb.edu.pl or aajduk@biol.uw.edu.pl \\ *( $R$ Milewski and A Ajduk contributed equally to this work)
}

\begin{abstract}
In vitro fertilization (IVF) is one of the most important procedures for treating infertility. As several embryos are usually produced in a single IVF cycle, it is crucial to select only the most viable ones for transfer to the patient. Morphokinetics, i.e. analysis of the dynamics of cleavage divisions and processes such as compaction and cavitation, has provided both biologists and clinicians with a new set of data regarding embryonic behaviour during preimplantation development and its association with embryo quality. In the current review, we focus on biological significance of morphokinetic parameters and show how they can be used to predict a reproductive outcome. We also explain the statistics behind the predictive algorithms and discuss the future perspectives of morphokinetics.

Reproduction (2017) 154 R37-R53
\end{abstract}

\section{Introduction}

Since 1978, when the first in vitro conceived baby was born (Steptoe \& Edwards 1978), in vitro fertilization (IVF) has become one of the most important procedures for treating infertility. In the UK in the last two decades, the number of IVF cycles has increased over three times, from 18,338 in 1992 to 63,573 in 2014 (according to the Human Fertility and Embryology Authority (HFEA), www.hfea.gov.uk). A similar tendency has also been observed in the USA, where the number of IVF cycles increased from 64,681 in 1996 to 188,023 in 2014 (according to the Society of Assisted Reproductive Technologies (SART), www.sart.org). Although IVF procedures have been greatly improved over the years, their efficiency, measured as the live birth rate, is still below $50 \%$. It ranges from $4.3 \%$ (UK) $/ 3.7 \%$ (US) for patients older than 42 to $32.8 \%$ (UK) $/ 48.7 \%$ (US) for women younger than 35 (data from 2013, HFEA and 2014, SART respectively). The efficiency of IVF can be elevated by transferring multiple (usually no more than 3 ) embryos in a single cycle, but this often results in multiple-pregnancies and as a consequence, in serious health complications for mothers and their babies (Petterson et al. 1993, Yokoyama et al. 1995, Pharoah \& Cooke 1996, Walker et al. 2004, Ombelet et al. 2005). As a result, many countries have introduced policies limiting the number of embryos that can be transferred in a single cycle and facilitating an elective single embryo transfer (eSET). Therefore, scientists and the medical industry are under constant pressure to develop novel, reliable methods to select high-quality embryos for transfer.

Recently, novel selection procedures based on timelapse imaging have been added to the embryo assessment toolkit. Although microscopic visualisation has been used for scoring embryos from the very beginning of IVF treatment, thus far embryos have been screened for specific morphological features only at certain time-points of their culture, and information about developmental dynamics (so-called morphokinetics) has been inaccessible (Ajduk \& Zernicka-Goetz 2013, Basile et al. 2015a). Integration of high resolution imaging equipment into a fully functional incubator has finally enabled embryo-safe recording of the cleavage divisions (Nakahara et al. 2010, Pribenszky et al. 2010, Cruz et al. 2011, Kirkegaard et al. 2012, Park et al. 2015). Although time-lapse imaging involves periodic exposure to light, it is usually lower than light exposure associated with traditional morphology assessment (Ottosen et al. 2007, Wong et al. 2010, Chen et al. 2013). Moreover, in contrast to a scoring protocol based on a visual inspection of embryo morphology performed outside an incubator, time-lapse imaging enables embryo culture in stable, uninterrupted conditions, which, as some researchers suggest, may be beneficial for embryo viability and the final reproductive outcome of the IVF procedure (Meseguer et al. 2012, Kirkegaard et al. 2015). 
However, there is no evidence that culture conditions ensured by time-lapse monitoring do indeed improve developmental potential of embryos; currently we can only state that they do not diminish it in any way (Cruz et al. 2011, Kirkegaard et al. 2012, Park et al. 2015). Yet, there is evidence that additional information about the dynamics of embryonic divisions, provided by time-lapse imaging, may help to select more viable embryos for transfer, leading to better reproductive outcomes (implantation and pregnancy rates) than a selection based on the traditional morphology assessment alone (Meseguer et al. 2012, Aparicio et al. 2013, Herrero \& Meseguer 2013, Findikli \& Oral 2014, Rubio et al. 2014, Siristatidis et al. 2015, AparicioRuiz et al. 2016). On the other hand, there are also reports showing that although morphokinetic parameters can predict embryo potential to achieve a blastocyst stage, neither implantation, nor pregnancy rate can be increased by morphokinetic analysis (Cruz et al. 2011, Kirkegaard et al. 2013, Polanski et al. 2014, Santos et al. 2014, Armstrong et al. 2015, Kirkegaard et al. 2015, Racowsky et al. 2015, Ahlstrom et al. 2016, Goodman et al. 2016, Kieslinger et al. 2016). Therefore, it is obvious that the usefulness of time-lapse imaging greatly depends on the accuracy of predictive models based on morphokinetic parameters. In the current review, we explain the biological significance of morphokinetic parameters and show how they can be used to model a reproductive outcome. We present the current state of research dedicated to establishing a morphokinetics-based embryo selection procedure. We compare the effectiveness of predictive models based on different statistical analysis methods and describe morphokinetic algorithms used in various IVF laboratories to predict preimplantation development, ploidy, implantation and clinical pregnancy. Finally, we discuss what is required to transform these locally-verifiable algorithms into a transferable and universally-effective embryo assessment protocol.

\section{Morphokinetic parameters and their biological significance}

Morphokinetic parameters include absolute timings of successive embryonic divisions, as well as relative timings, i.e. periods between divisions, reflecting either duration of the cell cycle or synchronisation of the cleavage rounds. The earliest time-points included in the morphokinetic analysis are tPB2, i.e. time of the 2nd polar body extrusion, marking a completion of 2 nd meiotic division; $\mathrm{tPNa}$, i.e. time when pronuclei appear, which reflects the beginning of the first embryonic interphase; $\mathrm{tPNf}$, i.e. time of pronuclei fading and the entry into the first embryonic M-phase. The $\mathrm{t} 2, \mathrm{t} 3, \mathrm{t} 4$, $\mathrm{t} 5$, $\mathrm{t} 6, \mathrm{t} 7, \mathrm{t} 8$ and $\mathrm{t} 9$ parameters are defined as the times for achieving the stage characterized by the corresponding number of cells ( $\mathrm{t} 2$ for 2 cells, $\mathrm{t} 3$ for 3 cells, etc.). The time $\mathrm{t} M$ is, on the other hand, defined as the first frame in which the embryo compacts (i.e. the clear boundaries between blastomeres disappear). The tSB time-point is marked by the appearance of a blastocoel cavity, tEB - by the onset of blastocyst expansion (i.e. increase in the overall embryo volume) and $\mathrm{tHB}$ - by the beginning of the blastocyst hatching, i.e. escaping from the zona pellucida encapsulation (Fig. 1A). Calculation of these absolute timings requires a starting time-point, set usually as the moment of fertilization (t0). In the case of intracytoplasmic sperm injection (ICSI), it is the moment of sperm injection. However, in the case of traditional IVF, when eggs are simply co-incubated with spermatozoa, determination of the exact timepoint of fertilization is much more difficult. to is then often defined as the beginning of insemination, and thus times of embryonic divisions tend to be longer than in ICSI, because spermatozoa penetrate oocytes sometime after the onset of insemination (Lemmen et al. 2008, Cruz et al. 2013, Liu et al. 2015b, Kirkegaard et al. 2016). When the absolute times of embryonic divisions are calculated in relation to another time-point, such as tPNf, the differences between IVF and ICSI disappear (Cruz et al. 2013, Liu et al. 2015b).

The starting time-point is not required when periods between embryonic divisions are calculated. A period between $\mathrm{t} 2$ and $\mathrm{t} 3$ is called cc 2 and reflects the length of cell cycle of the blastomere at the 2-cell stage. The length of the blastomere cell cycle at the 4-cell stage (cc3) is estimated as the difference between $\mathrm{t} 3$ and $\mathrm{t} 5$, and the length of the blastomere cell cycle at the 8-cell stage (cc4) - between $\mathrm{t} 5$ and $\mathrm{t} 9$. However, it must be pointed out that the last two parameters do not always reflect the real length of the cell cycle, because the first two blastomeres that originate from e.g. 2- to 4-cell transition are not always the first ones to divide in the next cleavage round. Periods between divisions can also provide information about cleavage synchronicity. For example, s2 is the difference between $\mathrm{t} 3$ and $\mathrm{t} 4$ and reflects synchronicity of the 2 nd round of cleavage divisions. Analogically, s3, the synchronicity of the $3 \mathrm{rd}$ round of cleavage divisions, can be calculated as the difference between $\mathrm{t} 5$ and $\mathrm{t} 8$.

It has been shown that both cleavage divisions that are too fast or too slow reflect poor developmental potential of the human embryo (Meseguer et al. 2011, Basile \& Meseguer 2012, Cruz et al. 2012, Chamayou et al. 2013, Herrero et al. 2013, Milewski et al. 2015). It is likely that timely divisions reflect good quality of the cytoplasmic component of the embryo: we can assume that activation events accompanying fertilization, such as $\mathrm{Ca}^{2+}$ oscillations, occurred correctly, that mitochondria provide sufficient amounts of energy, and that the cytoskeleton is functional. Although there are no studies directly linking those factors with the cell cycle length in blastomeres, they regulate such a wide spectrum of cellular processes that their impact 


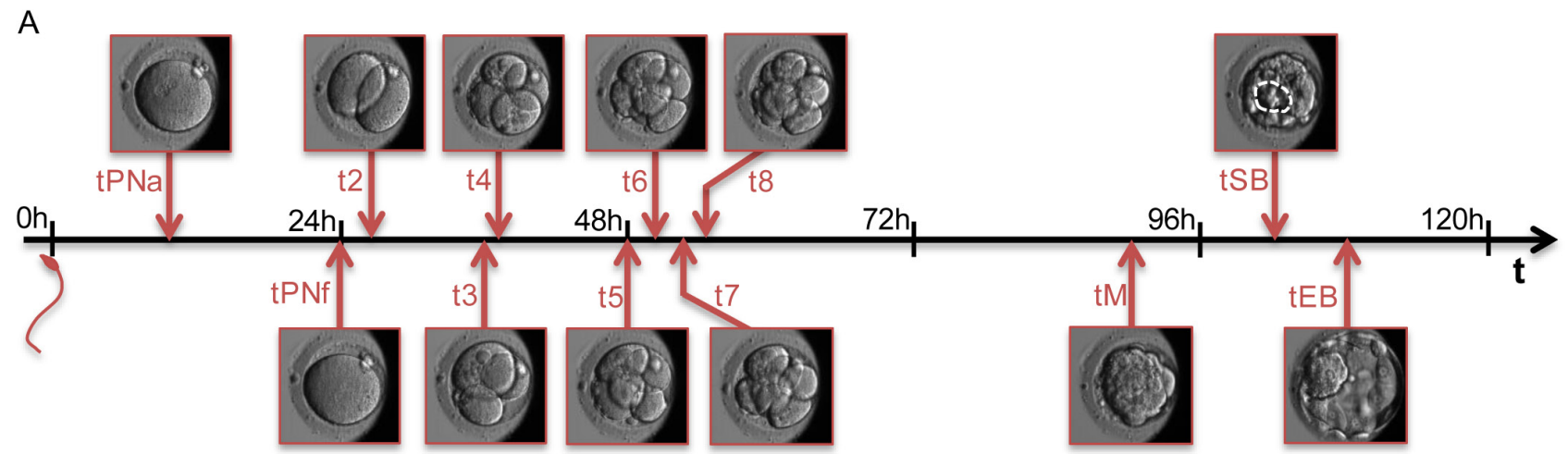

B
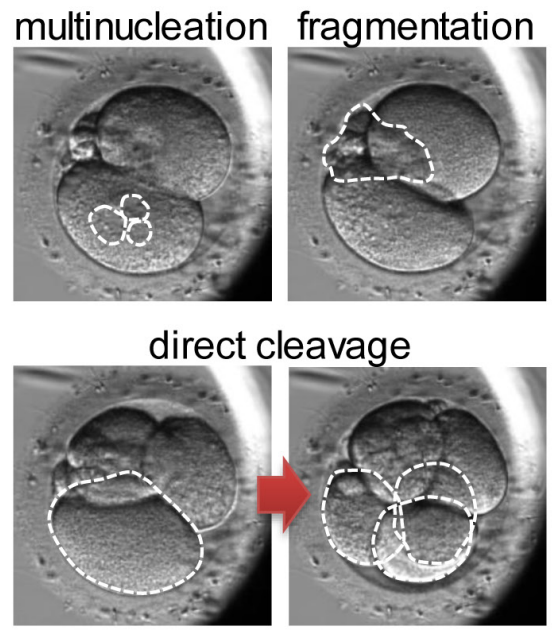

C
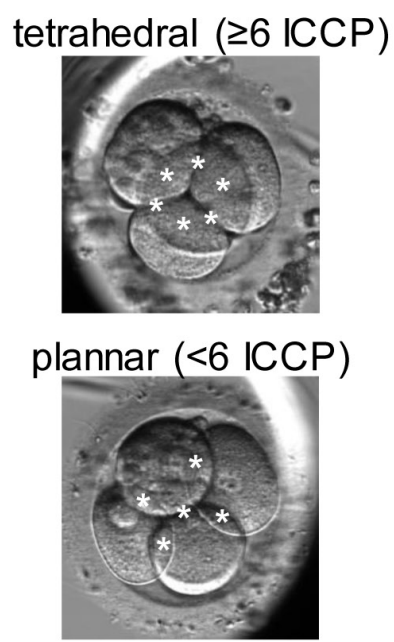

Figure 1 Morphokinetic parameters. (A) Morphokinetic timings and corresponding stages of human embryo development. Blastocoel cavity in a small blastocyst stage (tSB) marked with a white dashed line. (B) Examples of abnormal morphology in human embryos. White dashed line marks nuclei in the multinucleation panel, cytoplasmic fragments in the fragmentation panel and blastomeres in the direct cleavage panel. (C) Spatial arrangement of the blastomeres at the 4-cell stage. Intercellular contact points (ICCP) marked with asterisks.

on the cell cycle is inevitable. $\mathrm{Ca}^{2+}$ oscillations affect development of the embryo many days after fertilization, as they not only ensure monospermy, trigger completion of female meiosis and activate embryonic divisions, but also regulate mitochondrial activity, recruitment of maternal mRNAs and expression of embryonic genes (Dumollard et al. 2004, Ozil et al. 2005, 2006, Toth et al. 2006, Ducibella et al. 2006, Campbell \& Swann 2006). Mitochondria provide energy required for DNA synthesis and chromosome segregation (Salazar-Roa \& Malumbres 2017). The cytoskeleton, on the other hand, plays a key role in segregation of chromosomes, cytokinesis and cellular trafficking - each of them important for cell cycle progression (Tang 2012, D'Avino et al. 2015, Prosser \& Pelletier 2017).

It has also been suggested that timely divisions correspond to high-quality nuclear apparatus. Divisions that are too fast may result in incorrect segregation of the genetic material and lead to aneuploidy. On the other hand, divisions that are too slow may be a sign of DNA damage or chromosomal aberrations that activate one of the cell cycle checkpoints that halt the cell cycle progression. The G1/S, intra-S and G2/M checkpoints halt the progression of the interphase in response to DNA damage, enabling its repair (Sancar et al. 2004), whereas an M-phase checkpoint (the spindle assembly checkpoint or SAC) ensures equal segregation of genetic material to daughter cells and becomes activated if sister chromatids are incorrectly attached to spindle microtubules (Musacchio \& Salmon 2007, Nezi \& Musacchio 2009). However, sometimes the checkpoints fail, giving rise to cells with compromised genetic integrity. Interestingly, recent results obtained for mouse embryos indicate that missegregation of chromosomes does not strongly affect length of the cell cycle, at least at the 8- to 128-cell stages (Bolton et al. 2016, Vazquez-Diez et al. 2016). On the contrary, in human 1 - to 8-cell stage embryos aneuploidy seems to affect at least some division timings (Chavez et al. 2012, Vera-Rodriguez et al. 2015), indicating that there may be species- and/or stage-related differences in the regulation of blastomere reaction to ploidy defects. 
Time-lapse imaging also allows for assessment of morphological parameters, such as size of the blastomeres, number of nuclei in a blastomere, degree of fragmentation, and occurrence of irregular cleavages (Fig. 1B). Healthy human embryos have evenly sized blastomeres, as cells of different sizes suggest uneven segregation of the genetic material during division, an activated checkpoint, or failure of cytokinesis (when one blastomere is significantly, and persistently, bigger than the rest). Such blastomeres contain an incorrect number of chromosomes, sometimes even multiple nuclei, and this typically diminishes developmental potential of the embryo (Giorgetti et al. 1995, Ziebe et al. 1997, Hardarson et al. 2001, Ergin et al. 2014). Fragmentation, i.e. formation of membranebound extracellular cytoplasmic structures, also tends to correlate negatively with the embryo developmental potential and implantation rate (Giorgetti et al. 1995, Alikani et al. 1999, Campbell \& Fishel 2015, Yang et al. 2015). However, fragmentation is a part of programmed cell death, and as such it represents a way of eliminating blastomeres with severe genetic aberrations and does not necessarily have to be a bad prognostic (Jurisicova et al. 1996, Warner et al. 1998). Therefore, embryos with a low degree of fragmentation may still be considered as of good quality if other criteria, e.g. cleavage rate and blastomere shape, are fulfilled (Van Royen et al. 1999). Time-lapse imaging also detects direct or reverse cleavage divisions. Direct cleavage occurs when one blastomere divides directly into three or more daughter blastomeres. Sometimes this definition is extended to include so-called rapid cleavages, i.e. divisions from 2 to 3 blastomeres in less than $5 \mathrm{~h}$ (Rubio et al. 2012, Campbell \& Fishel 2015). Such irregular cleavages strongly correlate with impaired preimplantation development and implantation capacity (Rubio et al. 2012, Zaninovic et al. 2013, Athayde Wirka et al. 2014, Zaninovic et al. 2015). It is likely that direct cleavage reflects faulty spindle structure (caused, for example, by incorrect ploidy of the gametes or defective sperm centrosomes) and as a consequence uneven chromosomal segregation during division (Kola et al. 1987, Sathananthan 1998, Campbell \& Fishel 2015). Indeed, chromosomal abnormalities were detected in a majority of embryos that underwent direct cleavage (Chavez et al. 2012, Zaninovic et al. 2013, VeraRodriguez et al. 2015). Reverse cleavage, on the other hand, occurs when cytokinesis fails, or when two blastomeres fuse into a hybrid cell containing two nuclei (Balakier et al. 2000, Hickman et al. 2012, Campbell \& Fishel 2015). Reverse cleavage is probably caused by a decreased functionality of the cytoskeleton, especially its actomyosin component responsible for cytokinesis progression, or by a defect in the cell membrane, and it has been reported that it can be induced by cryopreservation (Balakier et al. 2000). Depending on the number of fused cells per embryo and the time-point when a reverse cleavage occurs, the embryos become either entirely polyploid (complete fusion at the 2- or 3-cell stage) or mosaic (i.e. built of normal and polyploid cells). Therefore, the effect of reverse cleavage on the embryo quality may vary between embryos (Hickman et al. 2012, Liu et al. 2014).

Additionally, time-lapse imaging provides data on the spatial arrangement of the blastomeres, which may also be predictive of the human embryo's developmental potential (Fig. 1C). At the 4-cell stage, a majority of embryos display tetrahedral geometry (i.e. have at least 6 intercellular contact points (ICCPs)), but some of them are planar instead (i.e. have less than 6 ICCPs). It has been reported that planar arrangement is associated with a low rate of blastocyst formation and poor implantation and pregnancy likelihood (Ebner et al. 2012, Paternot et al. 2014, Liu et al. 2015a). On the other hand, according to Cauffman et al. (2014), although tetrahedral and planar embryos differ in their ability to form high quality blastocysts, they do not differ in terms of pregnancy rate. Research conducted on mouse embryos indicates that the low developmental potential exhibited by planar embryos may be related to the separation of animal and vegetal material during the first two rounds of cleavage divisions. In mice, a certain pool of the planar embryos consist of blastomeres that inherited either only animal or only vegetal material from the oocyte (i.e. underwent two rounds of subsequent equatorial divisions, so-called EE embryos, PiotrowskaNitsche \& Zernicka-Goetz 2005). Such EE embryos gave rise to viable pups in only $35 \%$ of cases, as compared to $84-91 \%$ efficiency observed for the rest of the embryos. It is still unknown which molecules distributed differentially along the animal-vegetal axis of the oocyte/ zygote could be responsible for the different cell fate of the blastomeres that inherited them. So far, the hormone leptin, transcription factor STAT3, growth factors TGFb2 and VEGF, and the apoptosis-associated proteins BCL-X and BAX have been proposed as possible candidates, but apart from the asymmetric localization of these proteins, there is no proof of a functional link between them and the developmental fate of the blastomeres (Antczak \& Van Blerkom 1997, 1999, Schulz \& Roberts 2011). There is, however, an increasing amount of evidence showing that mouse blastomeres at the 4-cell stage indeed differ between each other in their developmental fate and on a molecular level (Piotrowska-Nitsche et al. 2005, Torres-Padilla et al. 2007, Bischoff et al. 2008, Plachta et al. 2011, Burton et al. 2013, Tabansky et al. 2013, Goolam et al. 2016).

\section{Types of morphokinetic algorithms}

The morphokinetic parameters described above provide input information for reproductive heuristic models - algorithms that can predict chances of achieving a blastocyst stage, implantation, biochemical or clinical 
pregnancy, or a full term development by each examined embryo. It has also been suggested that morphokinetic algorithms may distinguish euploid from aneuploid embryos. In preimplantation development, only embryo quality, related to the quality of gametes, matters, and therefore, heuristic morphokinetic models predicting an embryo's ability to cavitate are relatively efficient and reliable. Such models can be applied to select embryos for transfer at the 2nd-3rd day post fertilization and therefore minimalize the need for an extended, 5-6 day long in vitro culture. Importantly, it has been suggested that a prolonged embryo culture may have a negative influence on embryo quality, altering, among others, its epigenetic modification profile (Rinaudo \& Schultz 2004, Rinaudo et al. 2006, Market-Velker et al. 2010). Thus, a shorter embryo culture is likely to facilitate effectiveness of the IVF treatment, not to mention that it also decreases costs of the procedure. Morphokinetic algorithms modelling chances for pregnancy, assessed biochemically (by a pregnancy test), by the presence of embryonic sacs, an embryonic heartbeat or by live birth, are less predictive. This is caused by the fact that apart from the embryo quality, pregnancy depends on other factors, such as hormonal levels or endometrium responsiveness, which are usually excluded from the model. Reliable morphokinetic algorithms predicting ploidy are also difficult to construct. Although it seems likely that prolonged cell cycles or delayed or irregular divisions reflect various chromosomal aberrations, the association with the embryo ploidy (as assessed by standard preimplantation genetic screening or diagnosis procedures) is not always clear. It has been believed that chromosomal mosaicism of the embryo (some blastomeres are aneuploid, while others are euploid) may contribute to this situation, as it renders genetic analysis of biopsied cells not representative of the whole embryo (Harper et al. 1995, Munne et al. 1995, Bielanska et al. 2002, van Echten-Arends et al. 2011, Ajduk \& ZernickaGoetz 2013). However, the mere correlation between ploidy status and length of the blastomere cell cycle has also recently been disputed (Chavez et al. 2012, VeraRodriguez et al. 2015, Bolton et al. 2016, VazquezDiez et al. 2016).

In terms of mathematical methods used in morphokinetic algorithms, there are four main approaches (see also Boxes 1 and 2). The most basic algorithms are based on the analysis of one parameter and usually rely on simple correlations. They provide information about the influence of an examined parameter on the reproductive outcome, but such information very rarely has any prognostic value. Hierarchical algorithms are more complex; they take into consideration numerous parameters and establish their optimal value range. Depending on whether the parameter value fits within or outside this range, the prediction is more or less positive. Such algorithms are often used in IVF practice and their reliability has been repeatedly reported (Meseguer et al. 2011, Basile \& Meseguer 2012, Cruz et al. 2012, VerMilyea et al. 2014, Del Carmen Nogales et al. 2016, Motato et al. 2016, Patel et al. 2016). However, they have some disadvantages. First, the effect of each parameter on the final prediction strongly depends on their position in the hierarchy: parameters placed higher in the hierarchy affect the outcome to a greater extent than those with lower positions. A parameter's place in the hierarchy is

Box 1 Statistical methods used in reproductive modelling.

Regression - a statistical method that analyses associations between two or more variables and predicts unknown values of dependent variables (e.g. embryo's ability to achieve a blastocyst stage or to implant) based on known values of the independent (explanatory) variables (e.g. division timings). Depending on the number of explanatory variables used to predict the value of the dependent variable, we distinguish univariate (a single explanatory variable) and multivariate (at least two explanatory variables) regressions. Linear and logistic regressions are the most popular in biomedical sciences:

Linear regression estimates scalar value of a dependent variable (e.g. total number of embryo cells at the blastocyst stage) based on independent (explanatory) variables. Using this method, we assume a linear correlation between independent and dependent variables.

Logistic regression estimates binary value of a dependent variable (e.g. implantation/no implantation) based on independent (explanatory) variables.

Regression models require monotonic explanatory variables. A change of a monotonic explanatory variable in one direction (its increase or decrease) always leads to a change of the dependent variable in one direction also. Unfortunately, many morphokinetic parameters are non-monotonic, i.e. their effect on the dependent variable changes with their value. For example, cleavage divisions that are either too slow or too fast correlate with poor embryo quality, so an increase of the cleavage timings first increases the embryo quality, but beyond a certain value, it decreases it.

Hierarchical algorithm - a statistical, tree-structured algorithm that is very popular in reproductive medicine. Explanatory variables form 'nodes' that are connected with 'branches.' There are usually two branches growing from each node, and a decision, which branch should be chosen, depends on the value of the variable: whether or not it falls in the predetermined range. Nodes situated higher in the tree structure (i.e. closer to the starting node) have a greater impact on the outcome (e.g. embryo's ability to cavitate or implant).

Data-mining - a computational process of discovering patterns in large data sets involving methods at the intersection of artificial intelligence, machine learning, statistics and database systems.

Artificial intelligence - a branch of computer sciences drawing upon neuroscience, psychology and cognitivistics. It creates machines and software mimicking the cognitive abilities of the human mind that cannot be subjected to algorithmization.

Artificial neural networks - a computational artificial intelligence approach mimicking the way a biological brain solves problems. It is built as a network of neural units connected with each other like neurons in a brain. These systems are not explicitly programmed, but by feeding data into them, one can train them to analyse problems difficult to solve for conventional statistical methods. 
Box 2 Statistical significance of the reproductive models.

Odds ratio (OR) - a measure used, for example, in a logistic regression that quantifies the association between two variables. It is calculated as a ratio of odds that an outcome A (i.e. dependent variable A) occurs when a property B (i.e. explanatory variable B) is present to the odds of the outcome A occurring in the absence of property B. If the OR is greater than 1 , then the presence of $B$ raises (relative to the absence of B) the odds of having A, so these two parameters are associated. However, this does not necessarily mean that $B$ is a contributing cause of $\mathrm{A}$ : it could be associated with A through a third property, $\mathrm{C}$, which is the real contributing cause of both $\mathrm{A}$ and $\mathrm{B}$. This situation is typical for morphokinetics, e.g. timely cleavage divisions are associated with the implantation capability of the embryo, but they are not a contributing cause of this capability. Timely divisions reflect other cellular properties (correct ploidy, functional cytoskeleton, efficient energy metabolism, etc.) that are the real contributing causes of the embryo capability to implant.

Sensitivity - proportion of positive outcomes that are correctly identified by the model, e.g. the percentage of embryos that manage to implant and that were correctly identified as being able to do so.

Specificity - proportion of negative outcomes that are correctly identified by the model, e.g. the percentage of embryos that did not manage to implant and were correctly identified as being unable to do so.

Receiver Operating Characteristic (ROC) analysis - a graphical method assessing how well a scalar explanatory variable (e.g. division timings) predicts a binary outcome. It allows one to find the optimal threshold value of the explanatory variable, i.e. the value that distinguishes the two possible outcome situations (e.g. implantation/no implantation) in the best way. The ROC curve is created by plotting the true positive rate (or sensitivity) against the false positive rate (i.e. proportion of all negative outcomes classified as positive ones, calculated as $\mathbf{1}$ - specificity) at various threshold settings. Area under the curve (AUC) - a measure of the predictive power of a variable provided by the ROC (Receiver Operating Characteristic) method. It is calculated as an area under the ROC curve. AUC values range from 0.5 (when the explanatory variable is not at all associated with the analysed outcome) to 1 (when the variable with the chosen threshold value can distinguish two possible outcomes in $100 \%$ of cases). If AUC is lower than 0.5 , then the explanatory variable influences the outcome in the opposite direction, e.g. higher values of the explanatory variable correlate not with implantation, but with lack of implantation.

$\mathbf{9 5} \%$ confidence interval $(\mathbf{C I})$ - an estimated range of values which is likely to include the real value of the parameter of interest (e.g. AUC). In other words, if the experiment was repeated, our parameter would fall inside this range in $95 \%$ of cases. If $\mathrm{Cl}$ applies to AUC, it cannot include 0.5 value, otherwise it renders the association described by the algorithm statistically insignificant.

decided in a subjective way by a researcher. It usually does not have any deeper biological meaning, and it depends on its impact on the efficiency of the resulting algorithm. Second, in hierarchical algorithms, values inside the same value range (e.g. optimal or non-optimal range) have an equal power to affect the prediction. It does not matter whether the value is close to the minimum or maximum of the range, or whether it is close to its median. Moreover, values that are almost identical, but are situated at two sides of the range limit, have completely different impacts on the algorithm outcome. These flaws are not present in regression algorithms, in which the influence of each parameter on the outcome is not decided by a researcher, but depends on the obtained data. However, morphokinetic parameters are usually non-monotonic (i.e. both very low and very high values indicate poor embryo quality); therefore, they need to be mathematically transformed before being used in regression analysis. It has been proposed that the parameter values favoring the highest developmental potential are close to the median value calculated for the group of embryos with a positive outcome (i.e. achieving the blastocyst stage, implantation and live birth) (Milewski et al. 2015, 2016a, 2016b). Thus, non-monotonic parameters can be transformed to the distance between their value and the median, gaining the monotonic characteristics required for the regression models. The last type of morphokinetic algorithms is based on data-mining or artificial intelligence methods (e.g. artificial neural networks). These methods find associations between analysed parameters that cannot be easily uncovered by typical statistical procedures. Such algorithms provide outcomes without describing how each of the analysed parameters affects the result.
They simply adapt to the data, but it is impossible to identify the power and 'direction' of the parameter influence. Despite this flaw, algorithms applying artificial neural networks are probably the most potent tools in explaining biological processes and predicting biological outcomes, including outcome of IVF treatment (Milewski et al. 2009, Siristatidis et al. 2011).

\section{How to predict the ability to achieve a blastocyst stage?}

Many studies show that timings of human embryo divisions correlate with preimplantation development potential. Wong et al. (2010) correlated the human embryo's ability to achieve the blastocyst stage with (i) duration of the first cytokinesis (the very brief last step in mitosis that physically separates the two daughter cells), (ii) time interval between the end of the first division and the initiation of the second (the length of the 2 nd cell cycle, $\mathrm{cc} 2=\mathrm{t} 3-\mathrm{t} 2$ ) and (iii) the time interval between the second and third divisions (synchronicity of the 2 nd round of divisions, $s 2=t 4-t 3)$. Ability of embryos to reach the blastocyst stage could be predicted, with a sensitivity and specificity of $94 \%$ and $93 \%$ respectively, by having a first cytokinesis of $0-33 \mathrm{~min}, \mathrm{cc} 2$ of $7.8-14.3 \mathrm{~h}$ and s2 of $0-5.8 \mathrm{~h}$ (Wong et al. 2010). Further independent research (including a prospective multicentre study) has confirmed the usefulness of the cc2 and s2 parameters: they differed significantly between embryos that did or did not develop to the blastocyst stage and could be applied to predict implantation and pregnancy (Cruz et al. 2012, Conaghan et al. 2013, VerMilyea et al. 2014, Aparicio-Ruiz et al. 2016). Another prospective study 
positively verified the duration of the first cytokinesis as a biomarker of an embryo's ability to form high-quality blastocysts (Kirkegaard et al. 2013).

Cetinkaya et al. (2015) found that although most absolute and relative timings up to Day 3 of development differed between human embryos that later would form good or bad quality blastocysts, more complex parameters, calculated as ratios of relative timings, namely: cleavage synchronicity from 4 to 8 cells (CS4-8 $=(\mathrm{t} 8-\mathrm{t} 5) /(\mathrm{t} 8-\mathrm{t} 4))$ and cleavage synchronicity from 2 to 8 cells $(\mathrm{CS} 2-8=((\mathrm{t} 3-\mathrm{t} 2)+(\mathrm{t} 5-\mathrm{t} 4)) /(\mathrm{t} 8-\mathrm{t} 2))$, were better indicators of blastocyst formation and quality, with CS2-8 reaching the highest predictive power (AUC $=0.786,95 \% \mathrm{Cl}: 0.772-0.800$, sensitivity: $83.43 \%$ and specificity: $62.46 \%$ ). In the case of the CS4-8 parameter, embryos that had a t8-t4 period significantly longer than t8-t5 (i.e. CS4-8 tending towards 0 ) were favoured. In other words, embryos with a relatively synchronous $3 \mathrm{rd}$ round of cleavage (i.e. short t8-t5 interval) and synchronous 2 nd round of cleavage (i.e. divisions to 3 - and 4-cell stage occurring at a similar time, which ensures the longest possible period between $\mathrm{t} 4$ and $\mathrm{t} 5$ ) had higher developmental chances. In the case of the CS2-8 parameter, embryos that spent a long time at the 2 - and 4-cell stages (high values of $\mathrm{t} 3-\mathrm{t} 2$ and $\mathrm{t} 5 \mathrm{-t} 4$ parameters), and therefore had CS2-8 tending towards 1 , were favoured. In other words: embryos with 2nd and $3 \mathrm{rd}$ rounds of cleavage occurring relatively synchronously (i.e. occupying a small percentage of the t8-t2 period) had higher developmental potential.

A composite parameter Sc created as a mathematical transformation of absolute cleavage times (t2 and t5) and the duration of the 2nd cell cycle (cc2) has also been used to predict blastocyst formation in an algorithm applying logistic regression analysis (Milewski et al. 2015). In this algorithm, t2, t5 and cc2 timings were assigned different scores $(0,1$, or 2$)$, depending on their values and corresponding likelihood of blastocyst formation $(0$ for the lowest and 2 for the highest likelihood). Then, these individual scores were multiplied by their corresponding odds ratios (ORs), forming the composite Sc parameter. Sc was very effective in predicting blastocyst formation with the AUC reaching 0.806 (95\% Cl: 0.747-0.864). Importantly, the algorithm was validated on the independent data set and reached similarly high predictive power $(\mathrm{AUC}=0.813,95 \% \mathrm{Cl}$ : 0.746-0.880) (Milewski et al. 2015).

Another algorithm predicting blastocyst quality has been based on a hierarchical analysis of the timing of division to the 5 -cell stage ( $\mathrm{t} 5$; the primary variable) and the synchrony of the 2 nd round of cleavage (s2 =t4t3; the secondary variable) (Cruz et al. 2012). The algorithm divided embryos into four categories (A-D) with decreasing likelihood of cavitation (from $77 \%$ for $\mathrm{A}$ to $53.6 \%$ for D) and formation of a good quality blastocyst (from $61.3 \%$ for A to $34.5 \%$ for D). If the value of the t5 parameter fell inside the optimal range (48.8-56.6h), the embryo was graded as A or B. If the value of $t 5$ fell outside the optimal range, the embryo was graded as $\mathrm{C}$ or $\mathrm{D}$. If $\mathrm{s} 2$ was within the optimal range $(\leq 0.76 \mathrm{~h})$, the embryo was graded as $\mathrm{A}$ or $\mathrm{C}$, depending on the t5 value; if s2 was $>0.76 \mathrm{~h}$, the embryo was graded $\mathrm{B}$ or $\mathrm{D}$, also depending on the $t 5$ value (Fig. 2A). Unfortunately, A-D embryos did not differ in their ability to implant, demonstrating that algorithms predicting preimplantation development do not necessarily have a clinical significance (Cruz et al. 2012).

Another hierarchical classification procedure has been proposed by Motato et al. (2016). Researchers set timing of morula formation ( $t M)$ as the primary variable and synchronicity of the 3 rd round of cleavage (s3 $=\mathrm{t} 8$ t5) as the secondary one, and divided embryos into 4 categories (A-D) with decreasing capacity to form blastocysts (from $84.4 \%$ for $A$ to $13.8 \%$ for D). If embryos exhibited tM values falling inside the optimal range of 81.28-96.00 h, then they were categorized as A or B; if $\mathrm{t} M$ was outside the optimal range, the embryos were graded as $\mathrm{C}$ or $\mathrm{D}$. If $\mathrm{s} 3$ was within the optimal range $(\leq 8.78 \mathrm{~h})$, embryos were graded as A or C, depending on tM. Analogically, if s3 was outside the optimal range, embryos were scored as B or D (Fig. 2B). Again, similar to the model by Cruz et al. (2012), the algorithm efficiently predicted the ability to cavitate (AUC $=0.849 ; 95 \%$ Cl: 0.835-0.854), but was not effective in predicting implantation rates (AUC $=0.546 ; 95 \% \mathrm{Cl}$ : 0.507-0.585) (Motato et al. 2016).

Yang et al. (2015), on the other hand, focused on morphological information obtained from time-lapse imaging. They created a hierarchical algorithm dividing embryos into 6 groups (A-F) with a decreasing likelihood of cavitation (from $94.8 \%$ for $A$ to $21.2 \%$ for $F, P<0.001$ ) and forming good quality blastocysts (from $70.8 \%$ for $A$ to $0 \%$ for $\mathrm{E}$ and $3.8 \%$ for $\mathrm{F}, P<0.001$ ). Category $\mathrm{A}$ embryos had only normal divisions in the first three cleavage rounds. B embryos exhibited minor abnormalities, such as distorted cytoplasm movement during division, formation of big cytoplasmic fragments and formation of uneven blastomeres, in all three cleavage rounds. C embryos displayed minor abnormalities in the first two cleavage rounds and major abnormalities, such as a developmental arrest of a blastomere, a direct cleavage, a disordered division (i.e. division of one blastomere was delayed and occurred only after the rest of the blastomeres completed the next round of cleavage) and extensive fragmentation, in the $3 \mathrm{rd}$ round of cleavage. D embryos showed minor abnormalities in the 1 st round of cleavage and one of the two blastomeres showed major irregularities in the 2 nd round. In E embryos, the 1st cleavage occurred with minor abnormalities, but both the 2-cell blastomeres displayed major abnormalities in the 2 nd round of cleavage divisions. Finally, $\mathrm{F}$ embryos showed major irregularities in the 1st cleavage (Fig. 2C). Interestingly, a prospective observational study showed that embryos from the A-D categories also differed in 
A

Cruz's algorithm:

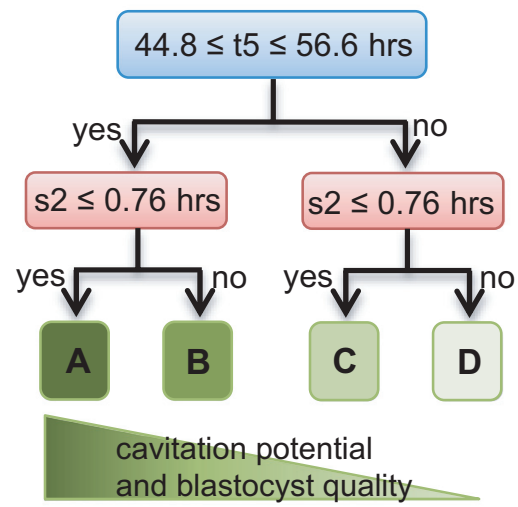

B

Motato's algorithm:

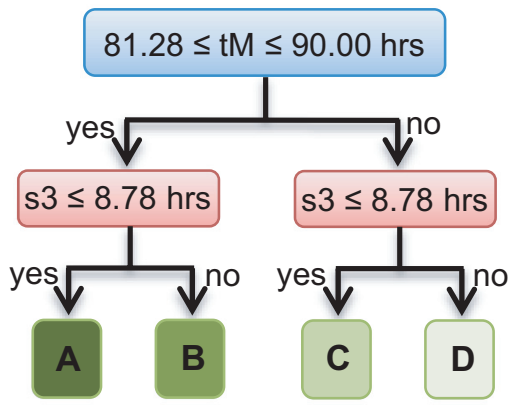

cavitation potential and blastocyst quality

\section{C}

Yang's algorithm:

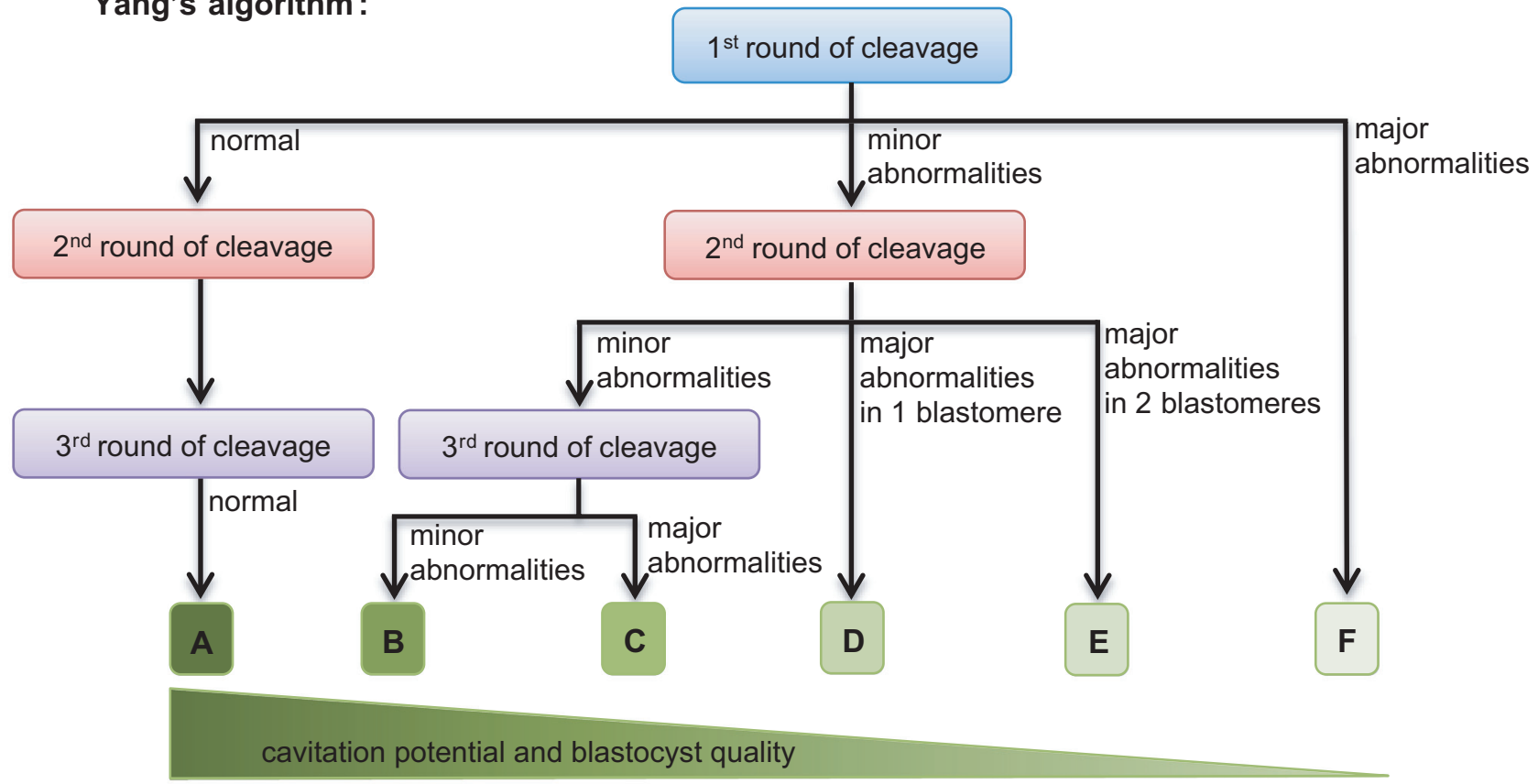

Figure 2 Morphokinetic algorithms predicting blastocyst formation and quality. Algorithms described by Cruz et al. (2012) (A), Motato et al. (2016) (B) and Yang et al. (2015) (C).

their ability to implant (from $67.0 \%$ for $A$ to $0 \%$ for D, $P<0.001$ ) (Yang et al. 2015).

To sum up, algorithms predicting blastocyst formation and quality focus on relatively early developmental events. Parameters describing length of a cell cycle in a 2-cell stage blastomere (cc2) or synchronicity of the 2nd round of cleavage (s2) seem to be particularly informative (Wong et al. 2010, Cruz et al. 2012, Conaghan et al. 2013). Indeed, if morphokinetic irregularities that, as we assume, reflect suboptimal condition of the cytoplasm and/or nuclear apparatus of the cell are detected in the early embryonic stages, the number of descendant blastomeres that may inherit the faulty components increases, compromising viability of the embryo more heavily. The same rule applies to morphological parameters such as fragmentation, irregular cleavages or developmental arrest: the earlier they occur, the greater their negative impact is on embryo quality (Yang et al. 2015). It is also important to note that morphokinetic algorithms strongly favour embryos that cleave synchronously, which, from the biological point of view, reflects undisturbed progression of the cell cycle in all blastomeres and, in consequence, minimizes the risks of, for example, DNA damage and chromosomal abnormalities (Wong et al. 2010, Cruz et al. 2012, Conaghan et al. 2013, Cetinkaya et al. 2015, Motato et al. 2016). Sadly, algorithms predicting preimplantation development of embryos are not very 
effective in selecting embryos with the highest likelihood of implantation or pregnancy, clearly demonstrating that a successful pregnancy requires more than just a morphokinetically faultless embryo.

\section{Going further: how to predict which embryo will successfully implant?}

The simplest algorithms predicting pregnancy use single parameters, both absolute and relative, such as time of nucleus appearance in the two blastomeres for 4-cell embryos, synchronicity of nuclear formation in both 2 -cell blastomeres, or synchronicity of the 2 nd round of cleavage division (s2 =t4-t3) (Lemmen et al. 2008). Parameters such as duration of 2-cell stage $(\mathrm{cc} 2=\mathrm{t} 3-$ t2) and synchronicity of the 2 nd round of cleavage $(\mathrm{s} 2=\mathrm{t} 4-\mathrm{t} 3)$ were also used for the selection of embryos with the highest implantation and pregnancy potential (VerMilyea et al. 2014). However, this approach has been questioned in a retrospective study by Kirkegaard et al. (2015) as generating false rejection rate that is too high (i.e. frequently disqualifying embryos that actually could have resulted in a pregnancy).

More complex algorithms apply a hierarchical analysis of multiple parameters. Meseguer et al. (2011) combined static evaluation of embryos with an assessment of dynamic parameters and divided embryos into ten categories $(\mathrm{A}+, \mathrm{A}-, \mathrm{B}+, \mathrm{B}-, \mathrm{C}+, \mathrm{C}-, \mathrm{D}+, \mathrm{D}-$, $\mathrm{E}$ and $\mathrm{F}$ ) with a decreasing likelihood of implantation (from $66 \%$ for $\mathrm{A}+$ to $8 \%$ for $\mathrm{E}$ grade; $\mathrm{F}$ embryos were not transferred, $A \cup C=0.72,95 \% \mathrm{Cl}: 0.645-0.795)$. The hierarchical classification procedure started with a morphological screening of the embryos: those that were clearly not viable (i.e. highly abnormal, attretic, etc.) were discarded and not considered for transfer and fell into the $\mathrm{F}$ category. The next step excluded embryos that fulfilled any of the three exclusion criteria: (i) uneven blastomere size at the 2-cell stage; (ii) direct division from one to three or more cells or (iii) multinucleation at the 4-cell stage (category E). Subsequently, the algorithm followed a strict hierarchy based on the timing variables $\mathrm{t} 5$, s2 (t4-t3) and cc2 (t3-t2). First, if the value of $\mathrm{t} 5$ fell inside the optimal range (48.8-56.6h), the embryo was categorized as $\mathrm{A}$ or $\mathrm{B}$. If the value of t5 fell outside the optimal range, the embryo was categorized as $\mathrm{C}$ or $\mathrm{D}$. If the value of $\mathrm{s} 2$ fell inside the optimal range $(\leq 0.76 \mathrm{~h})$, the embryo was categorized as A or $\mathrm{C}$, depending on t5; similarly, if the value of s2 fell outside the optimal range, the embryo was categorized as B or D, depending on t5. Finally, the embryo was categorized with an extra plus if the value for cc2 was inside the optimal range $(\leq 11.9 \mathrm{~h})$ and was categorized with a minus if the value for $\mathrm{Cc} 2$ was outside the optimal range (Fig. $3 \mathrm{~A}$ ). The usefulness of this algorithm was validated by the same authors in a retrospective study on an independent data set (Meseguer et al. 2012) and in a randomized controlled trial (Rubio et al. 2014).
However, subsequent external retrospective studies did not confirm its high predictive power and even questioned whether any predictive algorithm can be used universally in IVF units (Freour et al. 2015, Liu et al. 2015c). Interestingly, a simplified version of Meseguer and coworkers's algorithm, utilizing only t5 and s2 parameters, has been positively validated by Freour et al. (2015).

The study conducted by Meseguer et al. (2011) was followed up by a modified hierarchical algorithm based on a larger data set (Basile et al. 2015b). This time the t3 parameter was set as a primary variable, followed by $\mathrm{cc} 2$ and $\mathrm{t} 5$. As a result, 10 categories $(\mathrm{A}+, \mathrm{A}-, \mathrm{B}+, \mathrm{B}-$, $\mathrm{C}+, \mathrm{C}-, \mathrm{D}+, \mathrm{D}-, \mathrm{E}$ and $\mathrm{F}$ ) with decreasing likelihood of implantation were distinguished (from 32\% for $\mathrm{A}+$ to $17 \%$ for $\mathrm{E}$ grade; $\mathrm{F}$ embryos were not transferred, $P<0.001$, $\mathrm{A} \cup \mathrm{C}=0.61, \mathrm{Cl} 95 \%$ : 0.574-0.638). As in Meseguer and coworkers's algorithm, the first two steps were based on morphological assessment of the embryos, and only the embryos that had passed the assessment were subjected to the hierarchical classification. First, if the value of t3 fell inside the optimal range (34-40h), the embryo was categorized as A or B. If the value of $\mathrm{t} 3$ fell outside the optimal range, the embryo was categorized as $\mathrm{C}$ or D. Next, if the value of cc2 fell inside the optimal range (9-12 h), the embryo was categorized as A or C, depending on t3; similarly, if the value of cc2 fell outside the optimal range, the embryo was categorized as B or D, depending on t3. Finally, the embryo was categorized with an extra plus if the value for $t 5$ was inside the optimal range (45-55 h) and was categorized with a minus if the value for $\mathrm{t} 5$ was outside the optimal range.

A combination of morphological assessment and morphokinetic data has also been used in a hierarchical algorithm described by Liu et al. (2016). They divided embryos into 7 categories $(A+, A, B, C, D, E, F)$ with decreasing implantation rates (from $52.9 \%$ for $\mathrm{A}$ to $0 \%$ for $F, A \cup C=0.762,95 \%$ Cl: 0.701-0.824). First, Day 3 embryos were scored according to their morphology: poor-quality embryos were categorized as F. The rest of the embryos were subjected to cleavage pattern analysis: if embryos underwent direct or reverse cleavages, or exhibited less than 6 intracellular contact sites (i.e. were planar) at the 4-cell stage, they were classified as E; otherwise, they were subjected to further examination. If embryos had less than 8-cells at $68 \mathrm{~h}$ post insemination, then they were categorized as D. In the rest of the embryos, synchronicity of the 2nd round of cleavage (s2 $=\mathrm{t} 4-\mathrm{t} 3$ ) was assessed and if it was longer than $0.84 \mathrm{~h}$, embryos were graded as C. In the rest of the embryos, the time between disappearance of pronuclei and the 5 -cell stage ( $\mathrm{t} 5$ - $\mathrm{tPNf}$ ) was measured and if it was longer than $28.01 \mathrm{~h}$, embryos were categorized as $\mathrm{B}$; if it fell inside the range of 24.67 and $28.01 \mathrm{~h}$ - they were graded as $\mathrm{A}$; and if it was shorter than 24.67 - they became A+ (Fig. 3B). The algorithm was also prospectively 


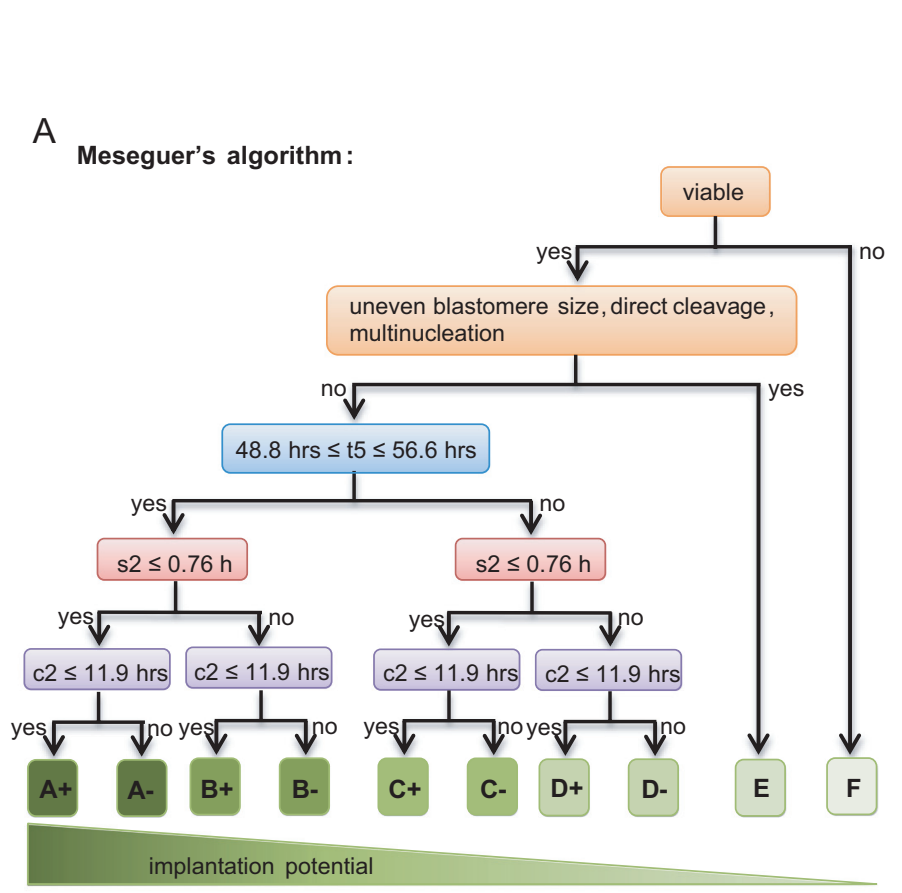

\section{B \\ Liu's algorithm:}
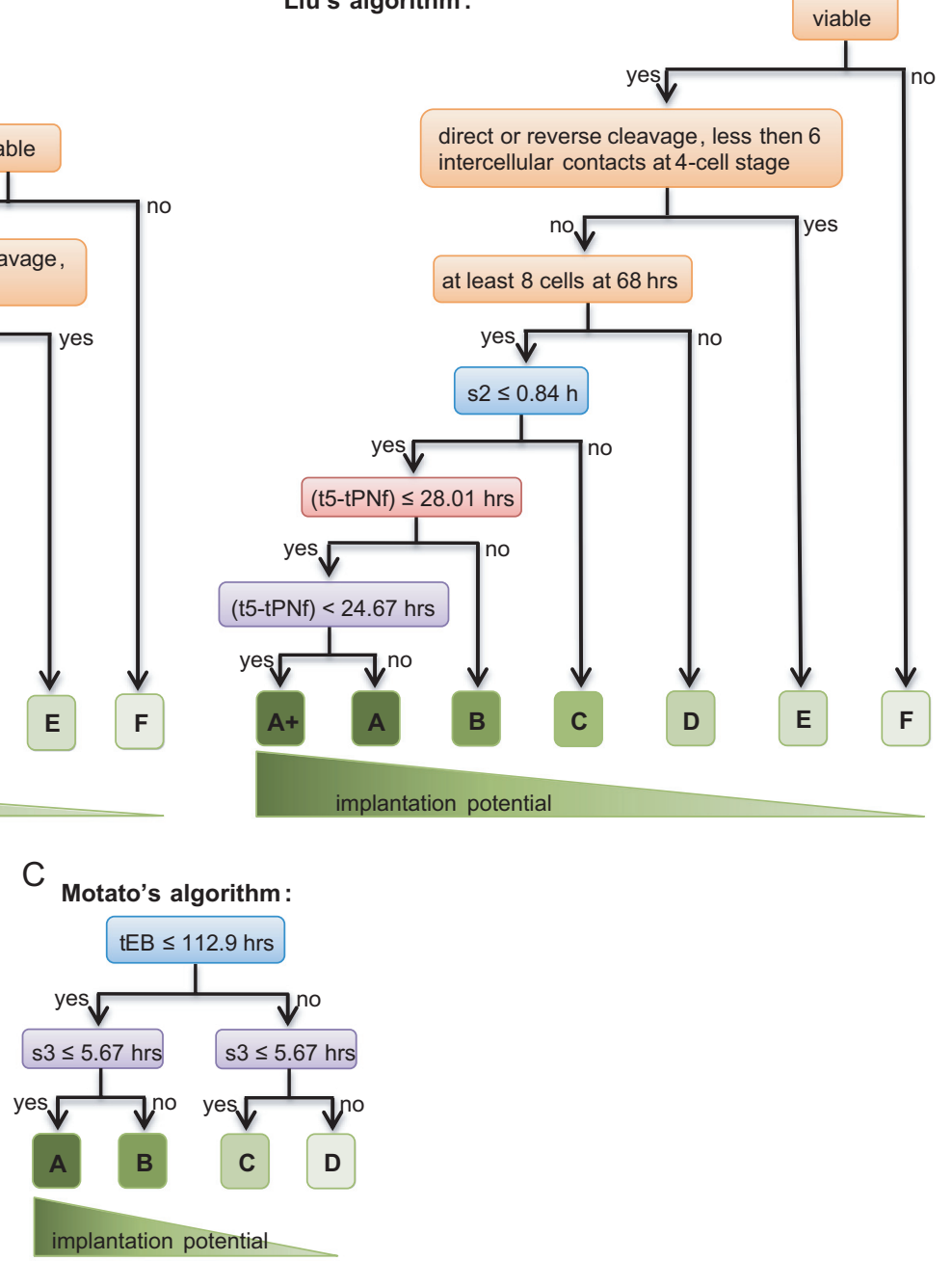

Figure 3 Morphokinetic algorithms predicting implantation and pregnancy. Algorithms described by Meseguer et al. (2011) (A), Liu et al. (2016) (B) and Motato et al. (2016) (C).

validated and, depending on the culture media used in the study, reached $\mathrm{AUC}=0.750$ (95\% Cl: 0.588-0.912) or $\mathrm{AUC}=0.820$ (95\% Cl: 0.671-0.969).

A simpler hierarchical algorithm was proposed byMotato et al. (2016). They set the timing of expanded blastocyst formation (tEB) as a primary variable with the optimal range of $\leq 112.9 \mathrm{~h}$, and synchronicity of the $3 \mathrm{rd}$ round of cleavage divisions ( $33=\mathrm{t} 8-\mathrm{t} 5)$ as the secondary variable with the optimal range of $\leq 5.67 \mathrm{~h}$. This approach divided embryos into 4 categories (A-D), with a decreasing implantation potential (from $72.2 \%$ for $\mathrm{A}$ to $39.7 \%$ for $\mathrm{D}, \mathrm{AUC}=0.591,95 \% \mathrm{Cl}$ : $0.552-$ 0.630) (Fig. 3C). While the algorithm was extended to include blastocyst morphology, oocyte donation, and age (patients' for their own oocytes and donors' for the donated oocytes), the AUC reached $0.602(95 \% \mathrm{Cl}$ : $0.559-0.645)$. The algorithm was positively validated on an independent data set $(\mathrm{AUC}=0.596,95 \% \mathrm{Cl}: 0.526-$ 0.666) (Motato et al. 2016)
Another approach utilized morphokinetic parameters such as division timings (from t2 to t5), the length of the 2nd cell cycle (cc2), and synchrony of the 2nd round of cleavage (s2) that were transformed to a set of monotonic, uncorrelated variables, and combined them with a fragmentation rate at $\mathrm{t} 3$ and female age (as an adjusting variable) (Milewski et al. 2016a). A multivariate regression analysis based on these parameters predicted pregnancy with a very high probability $(A \cup C=0.70$, 95\% Cl: 0.64-0.75). Importantly, the algorithm was validated on an independent data set and the obtained results were very similar $(\mathrm{AUC}=0.70,95 \% \mathrm{Cl}: 0.59$ 0.80 ), proving that it is reliable and applicable in clinical practice (Milewski et al. 2016a). t2-t5 division timings, s2 and cc2 were also used, this time together with morphological parameters such as fragmentation, multinucleation, blastomere size at $\mathrm{t} 2$ and $\mathrm{t} 4$, and female age, in a model applying the artificial neural network method (Milewski et al. 2017). In this case, 
the predictive power of the algorithm (AUC) reached $0.75(95 \% \mathrm{Cl}: 0.70-0.80)$ - a result that was confirmed by validation on an independent data set $(\mathrm{AUC}=0.71$, 95\% Cl: 0.59-0.84).

In summary, algorithms predicting implantation or pregnancy tend to be more complex than models selecting embryos according to their ability to form good quality blastocysts. However, surprisingly, they usually use the same parameters - cc2, s2, t5, often accompanied by another parameter referring to the early embryonic cleavages - t3 (Meseguer et al. 2011, Basile et al. 2015b, Liu et al. 2016, Milewski et al. 2016a, 2017). It is therefore difficult to explain, at least from the biological point of view, why they reflect implantation or pregnancy potential better than the simpler 'preimplantation algorithms'. It seems plausible that their higher efficiency towards detecting implantation/ pregnancy likelihood originates simply from the fact that they include more parameters and therefore set stricter criteria for embryo selection. Interestingly, implantation/pregnancy algorithms usually do not apply time parameters describing later developmental events, such as blastocoel formation or blastocyst expansion, and those that do (Motato et al. 2016) are not at all more efficient compared to the typical algorithms utilizing early morphokinetic parameters.

\section{Going deeper: how to predict ploidy of developing embryos?}

Several groups have attempted to create algorithms predicting aneuploidy in embryos based solely on noninvasive time-lapse monitoring instead of expensive and invasive genetic diagnostics. The rationale of this research is that embryos display different cleavage dynamics depending on their ploidy. However, the relationship between morphokinetic parameters and embryo ploidy is currently disputed (Chavez et al. 2012, Lammers et al. 2014, Chawla et al. 2015, Grau et al.
2015, Vera-Rodriguez et al. 2015, Bolton et al. 2016, Vazquez-Diez et al. 2016) and more research is definitely needed to solve this issue.

Basile et al. (2014), using a logistic regression analysis, showed that a combined duration of the 2-, 3- and 4-cell stage (t5-t2) and the length of the cell cycle in a 4-cell stage blastomere $(\mathrm{cc} 3=\mathrm{t} 5-\mathrm{t} 3)$ were the most relevant variables related to normal chromosomal content $(\mathrm{OR}=2.853 ; 95 \% \mathrm{Cl}: 1.763-4.616$ and $\mathrm{OR}=2.095 ; 95 \%$ Cl: $1.356-3.238$ respectively). A hierarchical algorithm based on t5-t2 and cc3 variables divided embryos into four categories (A-D), with an increasing percentage of chromosomal abnormalities (from $64.1 \%$ for $A$ to $90.2 \%$ for D category, $P<0.001, \mathrm{AUC}=0.634,95 \% \mathrm{Cl}$ : $0.581-0.687)$. If the $t 5-t 2$ value fell into the optimal range, defined as $>20.5 \mathrm{~h}$, the embryos were graded as $A$ or $B$; if the $t 5-t 2$ value was outside the optimal range, they were graded as $\mathrm{C}$ or $\mathrm{D}$. If the cc3 value was inside the optimal range (11.7-18.2 h), the embryos were graded as A or C, depending on t5-t2. Similarly, if cc3 fell out of the optimal range, the embryos were scored as $\mathrm{B}$ or $\mathrm{D}$, depending on $\mathrm{t} 5$-t2 (Fig. 4A). The $\mathrm{t} 5$-t2 variable is very interesting from the biological point of view, as it may distinguish embryos that cleaved to the 5-cell stage in a typical way (longer $\mathrm{t} 5 \mathrm{-t} 2$ interval) from those that underwent direct cleavages (from 1 - to 3-cells and/or 2to 5-cells) and, therefore, probably contain aneuploid blastomeres (shorter $\mathrm{t} 5-\mathrm{t} 2$ interval). Of course, the $\mathrm{t} 5$-t2 interval can also be prolonged if blastomeres progress through the cell cycle too slowly (e.g. due to activated cell cycle checkpoint) and then a longer t5-t2 period would be a bad prognostic. This contradiction was solved by addition of the cc3 parameter, which ensures that the best quality embryos have standard cell cycle length. The assumption that morphokinetic parameters in aneuploid embryos often display values outside the narrow range typical for euploid embryos has been also confirmed by Chavez et al. (2012), although different morphokinetic variables (length of the 1st cytokinesis, length of the cell-cycle at 2-cell stage $(\mathrm{cc} 2=\mathrm{t} 3-\mathrm{t} 2)$ and
A Basile's algorithm:

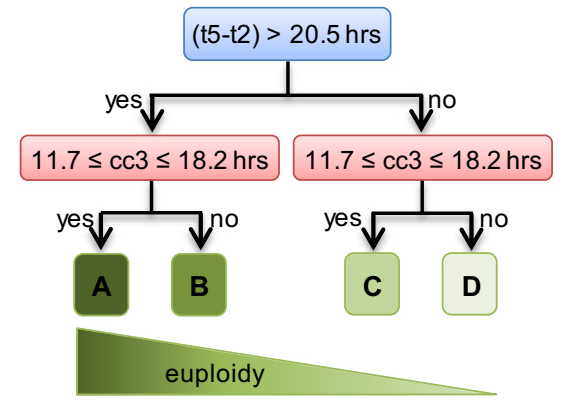

B Del Carmen Nogales's algorithm:

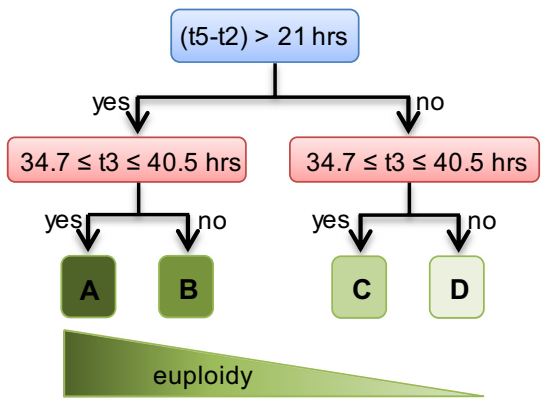

C Campbell's algorithm:

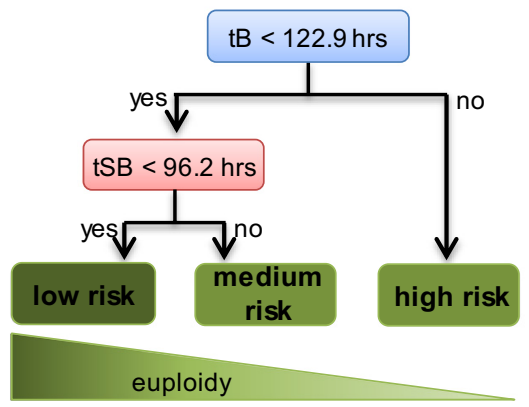

Figure 4 Morphokinetic algorithms predicting ploidy. Algorithms described by Basile et al. (2014) (A), Del Carmen Nogales (2016) (B) and Campbell et al. (2013a) (C). 
synchronicity of the 2 nd round of cleavage (s2 = t4-t3)) were examined in their study. The predictive power of both $\mathrm{t} 5 \mathrm{-t} 2$ and $\mathrm{cc} 3$ parameters was also confirmed by an independently performed univariate logistic regression analysis $(\mathrm{OR}=1.06 ; 95 \% \mathrm{Cl}: 1.03-1.09$ and $\mathrm{OR}=1.07$; 95\% Cl: 1.03-1.10 respectively). Embryos with t5-t2 longer than $20 \mathrm{~h}$ or with cc3 longer than $10 \mathrm{~h}$ were almost twice more likely to be euploid than embryos with $\mathrm{t} 5-\mathrm{t} 2$ or $\mathrm{Cc} 3$ shorter than these threshold times (Chawla et al. 2015). Patel et al. (2016), on the other hand, showed that although embryos having t5-t2 and cc3 parameters inside the optimal range proposed by Basile et al. (2014) are more likely to be euploid than embryos with those parameters outside the range, the differences were not statistically significant.

The $\mathrm{t} 5-\mathrm{t} 2$ parameter, this time combined with the $\mathrm{t} 3$ variable, has also been used in a hierarchical algorithm proposed by Del Carmen Nogales et al. (2016). Researchers divided embryos into 4 categories (A-D) with a decreasing likelihood of euploidy (from $70.6 \%$ for $\mathrm{A}$ to $14.6 \%$ for $\mathrm{D}, P<0.01)$. According to the algorithm, if the value of $\mathrm{t} 5 \mathrm{-t} 2$ was inside the optimal range, i.e. $>21 \mathrm{~h}$, the embryo was categorized as $\mathrm{A}$ or $B$; if the value of $t 5-t 2$ was outside the range, it was graded as $\mathrm{C}$ or $\mathrm{D}$. If $\mathrm{t} 3$ value was inside the optimal range of 34.7-40.5 h, embryos were categorized as A or $\mathrm{C}$, depending on $\mathrm{t} 5-\mathrm{t} 2$. Analogically, if the $\mathrm{t} 3$ value was outside the optimal range, embryos were graded as B or $\mathrm{D}$, depending on $\mathrm{t} 5 \mathrm{-t} 2$ (Fig. $4 \mathrm{~B}$ ). Here, the $\mathrm{t} 3$ parameter played a role similar to cc3 in the Basile and coworkers's algorithm: it ensured that the cell cycle (this time at the 2-cell stage) had a standard, 'healthy' length.

Ploidy has also been predicted based on later developmental time-points, such as tSB (start of blastulation) and $\mathrm{tB}$ (formation of a full blastocyst) (Campbell et al. 2013a). Embryos with $\mathrm{tB}<122.9 \mathrm{~h}$ and $\mathrm{tSB}<96.2 \mathrm{~h}$ were found to be at a low risk of aneuploidy $(37 \%)$; embryos with $\mathrm{tB}<122.9 \mathrm{~h}$ and $\mathrm{tSB}>96.2 \mathrm{~h}$ were at a medium risk $(69 \%)$; and with $\mathrm{tB}>122.9 \mathrm{~h}-$ at a high risk (97\%) ( $A \cup C=0.72$; Fig. 4C). Campbell and coworkers continued their studies in order to evaluate the effectiveness of this algorithm for pregnancy prediction in unselected IVF patients and found that embryos classified according to the abovementioned criteria as having low aneuploidy risk had a significantly higher potential to undergo foetal development compared to embryos classified as medium or high risk $(A \cup C=0.74$, Campbell et al. 2013b).

The algorithm created by Campbell et al. (2013a, 2013b) has raised a vivid discussion among clinicians and has been criticized for small sample size, lack of randomized control trial and a likely bias caused by maternal age (Ottolini et al. 2014). Even though researchers increased the sample size and refuted the objection that differences in $\mathrm{tSB}$ and $\mathrm{tB}$ timings among embryos reflect the maternal age rather than the ploidy status (Campbell et al. 2014), the dispute has continued.
Recently, the relevance of all published morphokinetic algorithms predicting aneuploidy has been questioned (Rienzietal.2015). Inthis newstudy, researchers examined a selected group of patients prone to aneuploidies and investigated a correlation between morphokinetic parameters obtained for individual embryos and their molecular karyotype assessed by trophectoderm biopsy and quantitative PCR screening of 24 chromosomes. Their results indicated that neither classification relying on $\mathrm{tSB}$ and $\mathrm{tB}$ timings (Campbell et al. 2013a, Campbell et al. 2013b, Campbell et al. 2014), nor hierarchical algorithm based on the interval between the two and five-cell stage (t2-t5) and the duration of the 3 rd cell cycle (cc3) (Basile et al. 2014, Chawla et al. 2015) allows one to distinguish chromosomally normal and abnormal embryos. This corresponds to the recent observation that aneuploid and euploid human embryos differ only in two morphokinetic parameters (up to the 8 -cell stage): duration of the 1 st mitotic phase $(P=0.025)$ and the synchrony of the 2 nd round of cleavage divisions $(\mathrm{s} 2=\mathrm{t} 4-\mathrm{t} 3) \quad(P=0.048) \quad($ Vera-Rodriguez et al. 2015). A lack of clear association between ploidy status and length of the blastomere cell cycle has also been reported for mouse embryos, although later cleavage divisions (from the 8- to 128-cell stage), which are usually not included in a standard morphokinetic analysis, were examined here (Bolton et al. 2016, Vazquez-Diez et al. 2016). Although these discrepancies may simply be caused by variations between laboratories and embryo culture systems (and in the case of mouse studies - by a difference between species), they emphasize the need for caution in interpretation of the data existing thus far and urge further, large-scale multicentre studies to clarify the possible relationship between cleavage dynamics and embryo ploidy.

\section{Challenges and perspectives of the morphokinetic models}

The last decade has brought a great advancement in the embryo-safe time-lapse imaging technique and use of predictive algorithms based on morphokinetics. Researchers have tested numerous morphokinetic parameters, used either individually or combined, and established which ones are strongly associated with good embryonic development, either to the blastocyst stage or full term. These results have been discussed in the present review. However, we are still at the beginning of our journey leading to the establishment of a universal, clinical morphokinetic algorithm for embryo selection. We have taken the first step: we have created algorithms that allow for effective embryo assessment in individual laboratories. Many of them fit the original set of data very well (AUC>0.7), but they are often not transferable to other embryo cohorts and fail the independent validation (see discussion between Meseguer et al. (2011) and Freour et al. (2015) and Liu et al. (2015c), 
or Campbell et al. (2013a, 2013b, 2014), Basile et al. (2014), Chawla et al. (2015) and Rienzi et al. (2015)). Therefore we need to make another step forward and focus our efforts on creation of an algorithm that would be effective in different clinics and that would take into consideration differences in IVF procedures (hormonal stimulation procedures, fertilization methods, culture media, etc.). To achieve this, we need to conduct extensive multi-centre validation studies of the morphokinetic algorithms and focus on finding parameters that have the highest inter-laboratory transferability.

Additionally, in order to maximize the predictive power of the reproductive outcome models, we should be continuing an intensive search for new biomarkers of embryonic quality. Studies in humans should be preceded by research on animal (preferably mammalian) models that allows for more extensive examination of molecular mechanisms governing embryo development. However, it must be emphasized that results obtained for animal models do not necessarily transfer directly to humans and that they should always be treated more as a mere indication of certain tendencies than a readyto-use solution. We should explore the possibility of combining time-lapse information with data provided by other diagnostic methods, such as genetic diagnostics, transcriptomics, proteomics or metabolomics (Yang et al. 2014, Dominguez et al. 2015, Tejera et al. 2016). Our data, obtained using a mouse model, indicate that morphokinetic parameters can also be combined with a time-lapse-based analysis of fertilization-induced rapid cytoplasmic motion (Ajduk et al. 2011) to predict quality of the resulting blastocysts (Ajduk \& Milewski, in preparation). In the case of pregnancy prediction, it is especially important to incorporate information related to the hormonal levels and endometrium condition, as they are important factors affecting implantation efficiency (Weimar et al. 2013, Atwood \& Vadakkadath Meethal 2016). Morphokinetic heuristic models can also be improved by replacement of simple regressive or hierarchical algorithms with algorithms based on data-mining and artificial intelligence methods (such as e.g. artificial neural networks), allowing more extensive utilization of the time-lapse data. Indeed, current biomedical research indicates that application of the artificial neural network method can maximize the predictive power of reproductive algorithms (Milewski et al. 2009, 2017).

In summary, heuristic models utilizing morphokinetic parameters in order to predict blastocyst formation, embryo ploidy or pregnancy are a promising noninvasive alternative to diagnostic methods used currently in clinical practice. Time-lapse imaging provides a broad spectrum of information related to embryo morphology and dynamics of embryonic divisions and undoubtedly gives clinicians new insights into the process of embryo preimplantation development. Although the models are still waiting for a thorough validation, and therefore need to be treated with caution, they unquestionably have great potential to support clinical assessment of human embryo quality.

\section{Declaration of interest}

The authors declare that there is no conflict of interest that could be perceived as prejudicing the impartiality of this review.

\section{Funding}

This work was supported by the SONATA grant (UMO2012/07/D/NZ5/04301) from the National Science Centre (Poland) to A A.

\section{References}

Ahlstrom A, Park H, Bergh C, Selleskog U \& Lundin K 2016 Conventional morphology performs better than morphokinetics for prediction of live birth after day 2 transfer. Reproductive Biomedicine Online 33 61-70. (doi:10.1016/j.rbmo.2016.03.008)

Ajduk A, Ilozue T, Windsor S, Yu Y, Seres KB, Bomphrey RJ, Tom BD, Swann K, Thomas A, Graham C et al. 2011 Rhythmic actomyosindriven contractions induced by sperm entry predict mammalian embryo viability. Nature Communications 2417 (doi:10.1038/ncomms1424)

Ajduk A \& Zernicka-Goetz M 2013 Quality control of embryo development. Molecular Aspects of Medicine 34 903-918. (doi:10.1016/j. mam.2013.03.001)

Alikani M, Cohen J, Tomkin G, Garrisi J, Mack C \& Scott RT 1999 Human embryo fragmentation in vitro and its implications for pregnancy and implantation. Fertility and Sterility 71 836-842. (doi:10.1016/S00150282(99)00092-8)

Antczak M \& Van Blerkom J 1997 Oocyte influences on early development: the regulatory proteins leptin and STAT3 are polarized in mouse and human oocytes and differentially distributed within the cells of the preimplantation stage embryo. Molecular Human Reproduction 3 1067-1086. (doi:10.1093/molehr/3.12.1067)

Antczak M \& Van Blerkom J 1999 Temporal and spatial aspects of fragmentation in early human embryos: possible effects on developmental competence and association with the differential elimination of regulatory proteins from polarized domains. Human Reproduction 14 429-447. (doi:10.1093/humrep/14.2.429)

Aparicio B, Cruz M \& Meseguer M 2013 Is morphokinetic analysis the answer? Reproductive Biomedicine Online 27 654-663. (doi:10.1016/j. rbmo.2013.07.017)

Aparicio-Ruiz B, Basile N, Perez Albale S, Bronet F, Remohi J \& Meseguer M 2016 Automatic time-lapse instrument is superior to single-point morphology observation for selecting viable embryos: retrospective study in oocyte donation. Fertility and Sterility 106 1379-1385.e10. (doi:10.1016/j.fertnstert.2016.07.1117)

Armstrong S, Vail A, Mastenbroek S, Jordan V \& Farquhar C 2015 Time-lapse in the IVF-lab: how should we assess potential benefit? Human Reproduction 30 3-8. (doi:10.1093/humrep/deu250)

Athayde Wirka K, Chen AA, Conaghan J, Ivani K, Gvakharia M, Behr B, Suraj V, Tan L \& Shen S 2014 Atypical embryo phenotypes identified by time-lapse microscopy: high prevalence and association with embryo development. Fertility and Sterility 101 1637-1648. e1-e5. (doi:10.1016/j.fertnstert.2014.02.050)

Atwood CS \& Vadakkadath Meethal S 2016 The spatiotemporal hormonal orchestration of human folliculogenesis, early embryogenesis and blastocyst implantation. Molecular and Cellular Endocrinology 430 33-48. (doi:10.1016/j.mce.2016.03.039)

Balakier H, Cabaca O, Bouman D, Shewchuk AB, Laskin C \& Squire JA 2000 Spontaneous blastomere fusion after freezing and thawing of early human embryos leads to polyploidy and chromosomal mosaicism. Human Reproduction 15 2404-2410. (doi:10.1093/humrep/15.11.2404) 
Basile N \& Meseguer M 2012 Time-lapse technology evaluation of embryo quality and new markers for embryo selection. Expert Review of Obstetrics \& Gynecology 7 175-190. (doi:10.1586/eog.12.8)

Basile N, del Carmen Nogales M, Bronet F, Florensa M, Riqueiros M, Rodrigo L, García-Velasco J \& Meseguer M 2014 Increasing the probability of selecting chromosomally normal embryos by timelapse morphokinetics analysis. Fertility and Sterility 101 699-704. (doi:10.1016/j.fertnstert.2013.12.005)

Basile N, Caiazzo M \& Meseguer M 2015a What does morphokinetics add to embryo selection and in-vitro fertilization outcomes? Current Opinion in Obstetrics and Gynecology 27 193-200. (doi:10.1097/ GCO.0000000000000166)

Basile N, Vime P, Florensa M, Aparicio Ruiz B, Garcia Velasco JA, Remohi J \& Meseguer M 2015b The use of morphokinetics as a predictor of implantation: a multicentric study to define and validate an algorithm for embryo selection. Human Reproduction 30 276-283. (doi:10.1093/ humrep/deu331)

Bielanska M, Tan SL \& Ao A 2002 Chromosomal mosaicism throughout human preimplantation development in vitro: incidence, type, and relevance to embryo outcome. Human Reproduction 17 413-419. (doi:10.1093/humrep/17.2.413)

Bischoff M, Parfitt DE \& Zernicka-Goetz M 2008 Formation of the embryonic-abembryonic axis of the mouse blastocyst: relationships between orientation of early cleavage divisions and pattern of symmetric/ asymmetric divisions. Development 135 953-962. (doi:10.1242/ dev.014316)

Bolton H, Graham SJL, Van der Aa N, Kumar P, Theunis K, Fernandez Gallardo E, Voet T \& Zernicka-Goetz M 2016 Mouse model of chromosome mosaicism reveals lineage-specific depletion of aneuploid cells and normal developmental potential. Nature Communications 7 11165 (doi:10.1038/ncomms11165)

Burton A, Muller J, Tu S, Padilla-Longoria P, Guccione E \& Torres-Padilla ME 2013 Single-cell profiling of epigenetic modifiers identifies PRDM14 as an inducer of cell fate in the mammalian embryo. Cell Reports $\mathbf{5}$ 687-701 (doi:10.1016/j.celrep.2013.09.044)

Campbell A \& Fishel S 2015 Atlas of Time Lapse Embryology. Taylor \& Francis Group. Boca Raton, London, New York: CRC Press.

Campbell A, Fishel S, Bowman N, Duffy S, Sedler M \& Hickman CF 2013 a Modelling a risk classification of aneuploidy in human embryos using non-invasive morphokinetics. Reproductive Biomedicine Online $\mathbf{2 6}$ 477-485. (doi:10.1016/j.rbmo.2013.02.006)

Campbell A, Fishel S, Bowman N, Duffy S, Sedler M \& Thornton S 2013b Retrospective analysis of outcomes after IVF using an aneuploidy risk model derived from time-lapse imaging without PGS. Reproductive Biomedicine Online 27 140-146. (doi:10.1016/j.rbmo.2013.04.013)

Campbell A, Fishel S \& Laegdsmand M 2014 Aneuploidy is a key causal factor of delays in blastulation: author response to 'A cautionary note against aneuploidy risk assessment using time-lapse imaging'. Reproductive Biomedicine Online 28 279-283. (doi:10.1016/j. rbmo.2013.11.016)

Campbell K \& Swann K $2006 \mathrm{Ca}^{2+}$ oscillations stimulate an ATP increase during fertilization of mouse eggs. Developmental Biology 298 225-233. (doi:10.1016/j.ydbio.2006.06.032)

Cauffman G, Verheyen G, Tournaye H \& Van de Velde H 2014 Developmental capacity and pregnancy rate of tetrahedral- versus nontetrahedral-shaped 4-cell stage human embryos. Journal of Assisted Reproduction and Genetics 31 427-434. (doi:10.1007/s10815-0140185-4)

Cetinkaya M, Pirkevi C, Yelke H, Colakoglu YK, Atayurt Z \& Kahraman S 2015 Relative kinetic expressions defining cleavage synchronicity are better predictors of blastocyst formation and quality than absolute time points. Journal of Assisted Reproduction and Genetics 32 27-35. (doi:10.1007/s10815-014-0341-x)

Chamayou S, Patrizio P, Storaci G, Tomaselli V, Alecci C, Ragolia C, Crescenzo C \& Guglielmino A 2013 The use of morphokinetic parameters to select all embryos with full capacity to implant. Journal of Assisted Reproduction and Genetics 30 703-710. (doi:10.1007/s10815013-9992-2)

Chavez SL, Loewke KE, Han J, Moussavi F, Colls P, Munne S, Behr B \& Reijo Pera RA 2012 Dynamic blastomere behaviour reflects human embryo ploidy by the four-cell stage. Nature Comminications 31251 (doi:10.1038/ncomms2249)
Chawla M, Fakih M, Shunnar A, Bayram A, Hellani A, Perumal V, Divakaran J \& Budak E 2015 Morphokinetic analysis of cleavage stage embryos and its relationship to aneuploidy in a retrospective time-lapse imaging study. Journal of Assisted Reproduction and Genetics 32 69-75. (doi:10.1007/s10815-014-0372-3)

Chen AA, Tan L, Suraj V, Reijo Pera R \& Shen S 2013 Biomarkers identified with time-lapse imaging: discovery, validation, and practical application. Fertility and Sterility 99 1035-1043. (doi:10.1016/j. fertnstert.2013.01.143)

Conaghan J, Chen AA, Willman SP, Ivani K, Chenette PE, Boostanfar R, Baker VL, Adamson GD, Abusief ME, Gvakharia M et al. 2013 Improving embryo selection using a computer-automated time-lapse image analysis test plus day 3 morphology: results from a prospective multicenter trial. Fertility and Sterility $100412-419$ e5. (doi:10.1016/j. fertnstert.2013.04.021)

Cruz M, Gadea B, Garrido N, Pedersen KS, Martinez M, Perez-Cano I, Munoz M \& Meseguer M 2011 Embryo quality, blastocyst and ongoing pregnancy rates in oocyte donation patients whose embryos were monitored by time-lapse imaging. Journal of Assisted Reproduction and Genetics 28 569-573. (doi:10.1007/s10815-011-9549-1)

Cruz M, Garrido N, Herrero J, Perez-Cano I, Munoz M \& Meseguer M 2012 Timing of cell division in human cleavage-stage embryos is linked with blastocyst formation and quality. Reproductive Biomedicine Online 25 371-381. (doi:10.1016/j.rbmo.2012.06.017)

Cruz M, Garrido N, Gadea B, Munoz M, Perez-Cano I \& Meseguer M 2013 Oocyte insemination techniques are related to alterations of embryo developmental timing in an oocyte donation model. Reproductive Biomedicine Online 27 367-375. (doi:10.1016/j.rbmo.2013.06.017)

D'Avino PP, Giansanti MG \& Petronczki M 2015 Cytokinesis in animal cells. Cold Spring Harbor Perspectives in Biology 7 a015834. (doi:10.1017/cbo9780511529764)

Del Carmen Nogales M, Bronet F, Basile N, Martínez EM, Linan A, Rodrigo L \& Meseguer M 2016 Type of chromosome abnormality affects embryo morphology dynamics. Fertility and Sterility (Epub ahead of print). (doi:10.1016/j.fertnstert.2016.09.019)

Dominguez F, Meseguer M, Aparicio-Ruiz B, Piqueras P, Quinonero A \& Simon C 2015 New strategy for diagnosing embryo implantation potential by combining proteomics and time-lapse technologies. Fertility and Sterility 104 908-914. (doi:10.1016/j.fertnstert.2015.06.032)

Ducibella T, Schultz RM \& Ozil JP 2006 Role of calcium signals in early development. Seminars in Cell and Developmental Biology 17 324-332. (doi:10.1016/j.semcdb.2006.02.010)

Dumollard R, Marangos P, Fitzharris G, Swann K, Duchen M \& Carroll J 2004 Sperm-triggered $\left[\mathrm{Ca}^{2+}\right]$ oscillations and $\mathrm{Ca}^{2+}$ homeostasis in the mouse egg have an absolute requirement for mitochondrial ATP production. Development 131 3057-3067. (doi:10.1242/dev.01181)

Ebner T, Maurer M, Shebl O, Moser M, Mayer RB, Duba HC \& Tews G 2012 Planar embryos have poor prognosis in terms of blastocyst formation and implantation. Reproductive Biomedicine Online 25 267-272. (doi:10.1016/j.rbmo.2012.05.007)

van Echten-Arends J, Mastenbroek S, Sikkema-Raddatz B, Korevaar JC, Heineman MJ, van der Veen F \& Repping S 2011 Chromosomal mosaicism in human preimplantation embryos: a systematic review. Human Reproduction Update 17 620-627. (doi:10.1093/humupd/ dmr014)

Ergin EG, Calişkan E, Yalçinkaya E, Oztel Z, Cökelez K, Ozay A \& Ozörnek HM 2014 Frequency of embryo multinucleation detected by time-lapse system and its impact on pregnancy outcome. Fertility and Sterility 102 1029-1033.e1. (doi:10.1016/j.fertnstert.2014.06.030)

Findikli N \& Oral E 2014 Time-lapse embryo imaging technology: does it improve the clinical results? Current Opinion in Obstetrics and Gynecology 26 138-144. (doi:10.1097/GCO.0000000000000072)

Freour T, Le Fleuter N, Lammers J, Splingart C, Reignier A \& Barriere P 2015 External validation of a time-lapse prediction model. Fertility and Sterility 103 917-922. (doi:10.1016/j.fertnstert.2014.12.111)

Giorgetti C, Terriou P, Auquier P, Hans E, Spach JL, Salzmann J \& Roulier R 1995 Embryo score to predict implantation after invitro fertilization: based on 957 single embryo transfers. Human Reproduction 10 2427-2431. (doi:10.1093/oxfordjournals.humrep. a136312)

Goodman LR, Goldberg J, Falcone T, Austin C \& Desai N 2016 Does the addition of time-lapse morphokinetics in the selection of embryos for 
transfer improve pregnancy rates? A randomized controlled trial. Fertility and Sterility 105 275-285.e10. (doi:10.1016/j.fertnstert.2015.10.013)

Goolam M, Scialdone A, Graham SJ, Macaulay IC, Jedrusik A, Hupalowska A, Voet T, Marioni JC \& Zernicka-Goetz M 2016 Heterogeneity in Oct4 and Sox2 targets biases cell fate in 4-cell mouse embryos. Cell $\mathbf{1 6 5}$ 61-74. (doi:10.1016/j.cell.2016.01.047)

Grau N, Escrich L, Galiana Y, Meseguer M, García-Herrero S, Remohi J \& Escriba MJ 2015 Morphokinetics as a predictor of self-correction to diploidy in tripronucleated intracytoplasmic sperm injection-derived human embryos. Fertility and Sterility 104 728-735. (doi:10.1016/j. fertnstert.2015.05.024)

Hardarson T, Hanson C, Sjogren A \& Lundin K 2001 Human embryos with unevenly sized blastomeres have lower pregnancy and implantation rates: indications for aneuploidy and multinucleation. Human Reproduction 16 313-318. (doi:10.1093/humrep/16.2.313)

Harper JC, Coonen E, Handyside AH, Winston RM, Hopman AH \& Delhanty JD 1995 Mosaicism of autosomes and sex chromosomes in morphologically normal, monospermic preimplantation human embryos. Prenatal Diagnosis 15 41-49. (doi:10.1002/pd.1970150109)

Herrero J \& Meseguer M 2013 Selection of high potential embryos using time-lapse imaging: the era of morphokinetics. Fertility and Sterility 99 1030-1034. (doi:10.1016/j.fertnstert.2013.01.089)

Herrero J, Tejera A, Albert C, Vidal C, de los Santos MJ \& Meseguer M 2013 A time to look back: analysis of morphokinetic characteristics of human embryo development. Fertility and Sterility 100 1602-1609. e1-e4. (doi:10.1016/j.fertnstert.2013.08.033)

Hickman CFL, Campbell A, Duffy S \& Fishel S 2012 Reverse Cleavage: its significance with regards to human embryo morphokinetics, ploidy and stimulation protocol. Human Reproduction 27 (Suppl. 2) ii103-ii105.

Jurisicova A, Varmuza S \& Casper RF 1996 Programmed cell death and human embryo fragmentation. Molecular Human Reproduction 2 93-98. (doi:10.1093/molehr/2.2.93)

Kieslinger DC, De Gheselle S, Lambalk CB, De Sutter P, Kostelijk EH, Twisk JW, van Rijswijk J, van den Abbeel E \& Vergouw CG 2016 Embryo selection using time-lapse analysis (Early Embryo Viability Assessment) in conjunction with standard morphology: a prospective two-center pilot study. Human Reproduction 31 2450-2457. (doi:10.1093/humrep/ dew207)

Kirkegaard K, Hindkjaer J, Grøndahl ML, Kesmodel US \& Ingerslev HJ 2012 A randomized clinical trial comparing embryo culture in a conventional incubator with a time-lapse incubator. Journal of Assisted Reproduction and Genetics 29 565-572 (doi:10.1007/s10815-0129750-x)

Kirkegaard K, Kesmodel US, Hindkjaer JJ \& Ingerslev HJ 2013 Time-lapse parameters as predictors of blastocyst development and pregnancy outcome in embryos from good prognosis patients: a prospective cohort study. Human Reproduction 28 2643-2651. (doi:10.1093/humrep/ $\operatorname{det} 300)$

Kirkegaard K, Ahlstrom A, Ingerslev HJ \& Hardarson T 2015 Choosing the best embryo by time lapse versus standard morphology. Fertility and Sterility 103 323-332. (doi:10.1016/j.fertnstert.2014.11.003)

Kirkegaard K, Sundvall L, Erlandsen M, Hindkjaer JJ, Knudsen UB \& Ingerslev HJ 2016 Timing of human preimplantation embryonic development is confounded by embryo origin. Human Reproduction 31 324-331. (doi:10.1093/humrep/dev296)

Kola I, Trounson A, Dawson G \& Rogers P 1987 Tripronuclear Human Oocytes: altered cleavage patterns and subsequent karyotypic analysis of embryos. Biology of Reproduction 37 395-401. (doi:10.1095/ biolreprod37.2.395)

Lammers J, Splingart C, Barriere P \& Freour T 2014 Morphokinetic parameters of ICSI tripronucleated embryos observed using time lapse. Reproductive BioMedicine Online 28 658-660. (doi:10.1016/j. rbmo.2014.01.009)

Lemmen JG, Agerholm I \& Ziebe S 2008 Kinetic markers of human embryo quality using time-lapse recordings of IVF/ICSI-fertilized oocytes. Reproductive Biomedicine Online 17 385-391. (doi:10.1016/S1472. 6483(10)60222-2)

Liu Y, Chapple V, Roberts P \& Matson P 2014 Prevalence, consequence, and significance of reverse cleavage by human embryos viewed with the use of the Embryoscope time-lapse video system. Fertility and Sterility 102 1295-1300. (doi:10.1016/j.fertnstert.2014.07.1235)
Liu Y, Chapple V, Feenan K, Roberts P \& Matson P 2015a Clinical significance of intercellular contact at the four-cell stage of human embryos, and the use of abnormal cleavage patterns to identify embryos with low implantation potential: a time-lapse study. Fertility and Sterility 103 1485-1491. (doi:10.1016/j.fertnstert.2015.03.017)

Liu Y, Chapple V, Feenan K, Roberts P \& Matson P 2015b Time-lapse videography of human embryos: Using pronuclear fading rather than insemination in IVF and ICSI cycles removes inconsistencies in time to reach early cleavage milestones. Reproductive Biology 201515 122-125. (doi:10.1016/j.repbio.2015.03.002)

Liu Y, Copeland C, Stevens A, Feenan K, Chapple V, Myssonski K, Roberts P \& Matson P 2015c Assessment of human embryos by time-lapse videography: a comparison of quantitative and qualitative measures between two independent laboratories. Reproductive Biology 15 210-216. (doi:10.1016/j.repbio.2015.09.001)

Liu Y, Chapple V, Feenan K, Roberts P \& Matson P 2016 Time-lapse deselection model for human day 3 in vitro fertilization embryos: the combination of qualitative and quantitative measures of embryo growth. Fertility and Sterility 105 656-662.e1. (doi:10.1016/j. fertnstert.2015.11.003)

Market-Velker BA, Fernandes AD \& Mann MR 2010 Side-by-side comparison of five commercial media systems in a mouse model: suboptimal in vitro culture interferes with imprint maintenance. Biology of Reproduction 83 938-950. (doi:10.1095/biolreprod.110.085480)

Meseguer M, Herrero J, Tejera A, Hilligsoe KM, Ramsing NB \& Remohi J 2011 The use of morphokinetics as a predictor of embryo implantation. Human Reproduction 26 2658-2671. (doi:10.1093/humrep/der256)

Meseguer M, Rubio I, Cruz M, Basile N, Marcos J \& Requena A 2012 Embryo incubation and selection in a time-lapse monitoring system improves pregnancy outcome compared with a standard incubator: a retrospective cohort study. Fertility and Sterility 98 1481-1489. (doi:10.1016/j.fertnstert.2012.08.016)

Milewski R, Jamiołkowski J, Milewska AJ, Domitrz J, Szamatowicz J \& Wołczyński S 2009 Prognosis of the IVF ICSI/ET procedure efficiency with the use of artificial neural networks among patients of the Department of Reproduction and Gynecological Endocrinology. Ginekologia Polska 80 900-906.

Milewski R, Kuć P, Kuczyńska A, Stankiewicz B, Łukaszuk K \& Kuczyński W 2015 A predictive model for blastocyst formation based on morphokinetic parameters in time-lapse monitoring of embryo development. Journal of Assisted Reproduction and Genetics 32 571-579. (doi:10.1007/s10815015-0440-3)

Milewski R, Milewska AJ, Kuczyńska A, Stankiewicz B \& Kuczyński W 2016 a Do morphokinetic data sets inform pregnancy potential? Journal of Assisted Reproduction and Genetics 33 357-365. (doi:10.1007/ s10815-016-0649-9)

Milewski R, Czerniecki J, Kuczyńska A, Stankiewicz B \& Kuczyński W $2016 b$ Morphokinetic parameters as a source of information concerning embryo developmental and implantation potential. Ginekologia Polska 87 677-684. (doi:10.5603/GP.2016.0067)

Milewski R, Kuczyńska A, Stankiewicz B \& Kuczyński W 2017 How much information about embryo implantation potential is included in morphokinetic data? A prediction model based on artificial neural networks and principal component analysis. Advances in Medical Sciences 62 202-206. (doi:10.1016/j.advms.2017.02.001)

Motato Y, de los Santos MJ, Escriba MJ, Ruiz BA, Remohi J \& Meseguer M 2016 Morphokinetic analysis and embryonic prediction for blastocyst formation through an integrated time-lapse system. Fertility and Sterility 105 376-384.e9. (doi:10.1016/j.fertnstert.2015.11.001)

Munne S, Sultan KM, Weier HU, Grifo JA, Cohen J \& Rosenwaks Z 1995 Assessment of numeric abnormalities of X, Y, 18 and 16 chromosomes in preimplantation human embryos before transfer. American Journal of Obstetrics and Gynecology 172 1191-1201. (doi:10.1016/00029378(95)91479-X)

Musacchio A \& Salmon ED 2007 The spindle-assembly checkpoint in space and time. Nature Reviews Molecular Cell Biology 8 379-393. (doi:10.1038/nrm2163)

Nakahara T, Iwase A, Goto M, Harata T, Suzuki M, lenaga M, Kobayashi H, Takikawa S, Manabe S, Kikkawa F et al. 2010 Evaluation of the safety of time-lapse observations for human embryos. Journal of Assisted Reproduction and Genetics 27 93-96. (doi:10.1007/s10815010-9385-8) 
Nezi L \& Musacchio A 2009 Sister chromatid tension and the spindle assembly checkpoint. Current Opinion in Cell Biology 21 785-795. (doi:10.1016/j.ceb.2009.09.007)

Ombelet W, De Sutter P, Van der Elst J \& Martens G 2005 Multiple gestation and infertility treatment: registration, reflection and reaction-the Belgian project. Human Reproduction Update 11 3-14. (doi:10.1093/humupd/ dmh048)

Ottolini C, Rienzi L \& Capalbo A 2014 A cautionary note against embryo aneuploidy risk assessment using time-lapse imaging. Reproductive Biomedicine Online 28 273-275. (doi:10.1016/j.rbmo.2013.10.015)

Ottosen LD, Hindkjaer J \& Ingerslev J 2007 Light exposure of the ovum and preimplantation embryo during ART procedures. Journal of Assisted Reproduction and Genetics 24 99-103. (doi:10.1007/s10815-0069081-x)

Ozil JP, Markoulaki S, Toth S, Matson S, Banrezes B, Knott JG, Schultz RM, Huneau D \& Ducibella T 2005 Egg activation events are regulated by the duration of a sustained $\left[\mathrm{Ca}^{2+}\right]_{\mathrm{cyt}}$ signal in the mouse. Developmental Biology 282 39-54 (doi:10.1016/j.ydbio.2005.02.035)

Ozil JP, Banrezes B, Toth S, Pan H \& Schultz RM $2006 \mathrm{Ca}^{2+}$ oscillatory pattern in fertilized mouse eggs affects gene expression and development to term. Developmental Biology 300 534-544. (doi:10.1016/j. ydbio.2006.08.041)

Park H, Bergh C, Selleskog U, Thurin-Kjellberg A \& Lundin K 2015 No benefit of culturing embryos in a closed system compared with a conventional incubator in terms of number of good quality embryos: results from an RCT. Human Reproduction 30 268-275. (doi:10.1093/ humrep/deu316)

Patel DV, Shah PB, Kotdawala AP, Herrero J, Rubio I \& Banker MR 2016 Morphokinetic behavior of euploid and aneuploid embryos analyzed by time-lapse in embryoscope. Journal of Human Reproductive Sciences 9 112-118. (doi:10.4103/0974-1208.183511)

Paternot G, Debrock S, De Neubourg D, D'Hooghe TM \& Spiessens C 2014 The spatial arrangement of blastomeres at the 4-cell stage and IVF outcome. Reproductive Biomedicine Online 28 198-203. (doi:10.1016/j. rbmo.2013.10.008)

Petterson B, Nelson KB, Watson L \& Stanley F 1993 Twins, triplets, and cerebral palsy in births in Western Australia in the 1980s. BMJ 307 1239-1243. (doi:10.1136/bmj.307.6914.1239)

Pharoah PO \& Cooke T 1996 Cerebral palsy and multiple births. Archives of Disease in Childhood Fetal \& Neonatal Edition 75 F174-F177. (doi:10.1093/ije/29.2.292)

Piotrowska-Nitsche K, Perea-Gomez A, Haraguchi S \& Zernicka-Goetz M 2005 Four-cell stage mouse blastomeres have different developmental properties. Development 132 479-490. (doi:10.1242/dev.01602)

Piotrowska-Nitsche K \& Zernicka-Goetz M 2005 Spatial arrangement of individual 4-cell stage blastomeres and the order in which they are generated correlate with blastocyst pattern in the mouse embryo. Mechanisms of Development 122 487-500. (doi:10.1016/j. mod.2004.11.014)

Plachta N, Bollenbach T, Pease S, Fraser SE \& Pantazis P 2011 Oct4 kinetics predict cell lineage patterning in the early mammalian embryo. Nature Cell Biology 13 117-123. (doi:10.1038/ncb2154)

Polanski LT, Coelho Neto MA, Nastri CO, Navarro PA, Ferriani RA, Raine-Fenning N \& Martins WP 2014 Time-lapse embryo imaging for improving reproductive outcomes: systematic review and meta-analysis. Ultrasound in Obstetrics \& Gynecology 44 394-401. (doi:10.1002/ uog.13428)

Pribenszky C, Matyas S, Kovacs P, Losonczi E, Zadori J \& Vajta G 2010 Pregnancy achieved by transfer of a single blastocyst selected by timelapse monitoring. Reproductive Biomedicine Online 21 533-536. (doi:10.1016/j.rbmo.2010.04.015)

Prosser SL \& Pelletier L 2017 Mitotic spindle assembly in animal cells: a fine balancing act. Nature Reviews Molecular Cell Biology 18 187-201. (doi:10.1038/nrm.2016.162)

Racowsky C, Kovacs P \& Martins WP 2015 A critical appraisal of timelapse imaging for embryo selection: where are we and where do we need to go? Journal of Assisted Reproduction and Genetics 32 1025-1030. (doi:10.1007/s10815-015-0510-6)

Rienzi L, Capalbo A, Stoppa M, Romano S, Maggiulli R, Albricci L, Scarica C, Farcomeni A, Vajta G \& Ubaldi FM 2015 No evidence of association between blastocyst aneuploidy and morphokinetic assessment in a selected population of poor-prognosis patients: a longitudinal cohort study. Reproductive Biomedicine Online 30 57-66. (doi:10.1016/j. rbmo.2014.09.012)

Rinaudo P \& Schultz RM 2004 Effects of embryo culture on global pattern of gene expression in preimplantation mouse embryos. Reproduction 128 301-311. (doi:10.1530/rep.1.00297)

Rinaudo PF, Giritharan G, Talbi S, Dobson AT \& Schultz RM 2006 Effects of oxygen tension on gene expression in preimplantation mouse embryos. Fertility and Sterility 86 1252-1265. (doi:10.1016/j. fertnstert.2006.05.017)

Rubio I, Kuhlmann R, Agerholm I, Kirk J, Herrero J, Escriba MJ, Bellver J \& Meseguer M 2012 Limited implantation success of direct-cleaved human zygotes: a time-lapse study. Fertility and Sterility 98 1458-1463. (doi:10.1016/j.fertnstert.2012.07.1135)

Rubio I, Galan A, Larreategui Z, Ayerdi F, Bellver J, Herrero J \& Meseguer M 2014 Clinical validation of embryo culture and selection by morphokinetic analysis: a randomized, controlled trial of the EmbryoScope. Fertility and Sterility 102 1287-1294. (doi:10.1016/j. fertnstert.2014.07.738)

Salazar-Roa M \& Malumbres M 2017 Fueling the cell division cycle. Trends in Cell Biology 27 69-81. (doi:10.1016/j.tcb.2016.08.009)

Sancar A, Lindsey-Boltz LA, Unsal-Kacmaz K \& Linn S 2004 Molecular mechanisms of mammalian DNA repair and the DNA damage checkpoints. Annual Review of Biochemistry 73 39-85. (doi:10.1146/ annurev.biochem.73.011303.073723)

de los Santos MJ, Arroyo G, Busquet A, Calderon G, Cuadros J, Hurtado de Mendoza MV, Moragas M, Herrer R, Ortiz A, Pons C et al. 2014 A multicenter prospective study to assess the effect of early cleavage on embryo quality, implantation, and live-birth rate. Fertility and Sterility 101 981-987. (doi:10.1016/j.fertnstert.2013.12.043)

Sathananthan AH 1998 Paternal centrosomal dynamics in early human development and infertility. Journal of Assisted Reproduction and Genetics 15 129-139. (doi:10.1023/A:1023056804548)

Schulz LC \& Roberts RM 2011 Dynamic changes in leptin distribution in the progression from ovum to blastocyst of the pre-implantation mouse embryo. Reproduction 141 767-777. (doi:10.1530/REP-10-0532)

Siristatidis C, Pouliakis A, Chrelias C \& Kassanos D 2011 Artificial intelligence in IVF: a need. Systems Biology in Reproductive Medicine 57 179-185. (doi:10.3109/19396368.2011.558607)

Siristatidis C, Komitopoulou MA, Makris A, Sialakouma A, Botzaki M, Mastorakos G, Salamalekis G, Bettocchi S \& Palmer GA 2015 Morphokinetic parameters of early embryo development via time lapse monitoring and their effect on embryo selection and ICSI outcomes: a prospective cohort study. Journal of Assisted Reproduction and Genetics 32 563-570. (doi:10.1007/s10815-015-0436-z)

Steptoe PC \& Edwards RG 1978 Birth after the reimplantation of a human embryo. Lancet 312 366. (doi:10.1016/S0140-6736(78)92957-4)

Tabansky I, Lenarcic A, Draft RW, Loulier K, Keskin DB, Rosains J, RiveraFeliciano J, Lichtman JW, Livet J, Stern JN, et al. 2013. Developmental bias in cleavage-stage mouse blastomeres. Current Biology 23 21-31. (doi:10.1016/j.cub.2012.10.054)

Tang BL 2012 Membrane trafficking components in cytokinesis. Cellular Physiology and Biochemistry 30 1097-1108. (doi:10.1159/000343301)

Tejera A, Castello D, de Los Santos JM, Pellicer A, Remohi J \& Meseguer M 2016 Combination of metabolism measurement and a time-lapse system provides an embryo selection method based on oxygen uptake and chronology of cytokinesis timing. Fertility and Sterility 106 119-126. e2. (doi:10.1016/j.fertnstert.2016.03.019)

Torres-Padilla ME, Parfitt DE, Kouzarides T \& Zernicka-Goetz M 2007 Histone arginine methylation regulates pluripotency in the early mouse embryo. Nature 445 214-218. (doi:10.1038/nature05458)

Toth S, Huneau D, Banrezes B \& Ozil JP 2006 Egg activation is the result of calcium signal summation in the mouse. Reproduction 131 27-34. (doi:10.1530/rep.1.00764)

Van Royen E, Mangelschots K, De Neubourg D, Valkenburg M, Van de Meerssche M, Ryckaert G, Eestermans W \& Gerris J 1999 Characterization of a top quality embryo, a step towards singleembryo transfer. Human Reproduction 14 2345-2349. (doi:10.1093/ humrep/14.9.2345)

Vázquez-Diez C, Yamagata K, Trivedi S, Haverfield J \& FitzHarris G 2016 Micronucleus formation causes perpetual unilateral chromosome inheritance in mouse embryos. PNAS 113 626-631. (doi:10.1073/ pnas.1517628112) 
Vera-Rodriguez M, Chavez SL, Rubio C, Reijo Pera RA \& Simon C 2015 Prediction model for aneuploidy in early human embryo development revealed by single-cell analysis. Nature Communications $\mathbf{6} 7601$ (doi:10.1038/ncomms8601)

VerMilyea MD, Tan L, Anthony JT, Conaghan J, Ivani K, Gvakharia M, Boostanfar R, Baker VL, Suraj V, Chen AA et al. 2014 Computer-automated time-lapse analysis results correlate with embryo implantation and clinical pregnancy: a blinded, multicentre study. Reproductive Biomedicine Online 29 729-736. (doi:10.1016/j. rbmo.2014.09.005)

Walker MC, Murphy KE, Pan S, Yang Q \& Wen SW 2004 Adverse maternal outcomes in multifetal pregnancies. BJOG 111 1294-1296. (doi:10.1111/j.1471-0528.2004.00345.x)

Warner CM, Cao W, Exley GE, McElhinny AS, Alikani M, Cohen J, Scott RT \& Brenner CA 1998 Genetic regulation of egg and embryo survival. Human Reproduction 13 178-190 (discussion 191-196). (doi:10.1093/ humrep/13.suppl_3.178)

Weimar CHE, Uiterweer EDP, Teklenburg G, Heijnen CJ \& Macklon NS 2013 In-vitro model systems for the study of human embryoendometrium interactions. Reproductive Biomedicine Online 27 461-476. (doi:10.1016/j.rbmo.2013.08.002)

Wong CC, Loewke KE, Bossert NL, Behr B, De Jonge CJ, Baer TM \& Reijo Pera RA 2010 Non-invasive imaging of human embryos before embryonic genome activation predicts development to the blastocyst stage. Nature Biotechnology 28 1115-1121. (doi:10.1038/nbt.1686)

Yang Z, Zhang J, Salem SA, Liu X, Kuang Y, Salem RD \& Liu J 2014 Selection of competent blastocysts for transfer by combining time-lapse monitoring and array $\mathrm{CGH}$ testing for patients undergoing preimplantation genetic screening: a prospective study with sibling oocytes. BMC Medical Genomics 7 38. (doi:10.1186/1755-8794-7-38)

Yang ST, Shi JX, Gong F, Zhang SP, Lu CF, Tan K, Leng LZ, Hao M, He H, Gu YF et al. 2015 Cleavage pattern predicts developmental potential of day 3 human embryos produced by IVF. Reproductive Biomedicine Online 30 625-634. (doi:10.1016/j.rbmo.2015.02.008)

Yokoyama Y, Shimizu T \& Hayakawa K 1995 Incidence of handicaps in multiple births and associated factors. Acta Geneticae Medicae et Gemellologiae 44 81-91. (doi:10.1017/S0001566000001744)

Zaninovic N, Ye Z, Zhan Q, Clarke R \& Rosenwaks Z 2013 Cell stage onsets, embryo developmental potential and chromosomal abnormalities in embryos exhibiting direct unequal cleavages (DUCs). Fertility and Sterility 100 S242. (doi:10.1016/j.fertnstert.2013.07.1223)

Zaninovic N, Zhan Q \& Rosenwaks Z 2015 Time-lapse implementation in a clinical setting: outcome results. In Time-Lapse Microscopy in In-Vitro Fertilization, Ed M Meseguer. Cambridge: Cambridge University Press.

Ziebe S, Petersen K, Lindenberg S, Andersen AG, Gabrielsen A \& Andersen AN 1997 Embryo morphology or cleavage stage: how to select the best embryos for transfer after in-vitro fertilization. Human Reproduction 12 1545-1549. (doi:10.1093/humrep/12.7.1545)

Received 3 January 2017

First decision 28 February 2017

Revised manuscript received 4 April 2017

Accepted 13 April 2017 